Research Article

\title{
Deterioration of the Internal Structure of Loess under Dry-Wet Cycles
}

\author{
Wanjun Ye, Yang Bai $\mathbb{D}^{\mathrm{D}}$, Chenyang Cui, and Xu Duan \\ School of Architecture and Civil Engineering, Xi'an University of Science and Technology, Xi'an, 710054 Shaanxi, China \\ Correspondence should be addressed to Yang Bai; baiyang19920613@163.com
}

Received 19 March 2020; Revised 30 May 2020; Accepted 18 June 2020; Published 16 July 2020

Academic Editor: Chunshun Zhang

Copyright (C) 2020 Wanjun Ye et al. This is an open access article distributed under the Creative Commons Attribution License, which permits unrestricted use, distribution, and reproduction in any medium, provided the original work is properly cited.

\begin{abstract}
To understand the structural damage evolution process of loess under the action of dry-wet cycles, a triaxial test of a dry-wet cycle was performed by considering three influencing factors: initial moisture content, amplitude of the dry-wet cycle, and number of dry-wet cycles. The stress-strain curves of undisturbed loess samples at different cycling times vary under different compacted loess cycles. Under the same axial strain, the stress value of the undisturbed loess is higher than that of the loess sample after a drywet cycle, indicating that such cycle can reduce the strength of loess. As the number and amplitude of dry-wet cycles increase, the shear strength of the loess sample and the value of cohesion $(c)$ of the strength index gradually decrease, and the amplitude gradually decreases. With an increase in the number and amplitude of dry-wet cycles, the change in the internal friction angle of the strength index is inevident, indicating that the effect of dry-wet cycles on the internal friction angle of loess is insignificant. Computed tomography (CT) scan experiments were also conducted to obtain the evolution of loess cracks before and after a drywet cycle. Studies have shown that as the number and amplitude of dry-wet cycles increase, the mean (ME) value of CT decreases, the standard deviation (SD) value increases, and the ME value is obtained during the initial stage of a dry-wet cycle. Meanwhile, the decreasing trend of ME and the increasing trend of SD values are most evident during the period of a dry-wet cycle. In conclusion, dry-wet cycles promote the development of cracks.
\end{abstract}

\section{Introduction}

In Northwest China, loess is distributed continuously and widely, with thick strata. Loess in this region is typical Quaternary loose sediment with the best development and the most complete strata $[1,2]$. Given the rapid economic development in Northwest China, the construction of various cities and the expansion of railways, highways, and water conservation projects have resulted in varying degrees of damage to the loess area. Geological disasters, such as collapse and landslides, frequently occur and affect the progress of construction projects or the safe use of engineering buildings. Especially in recent years, due to the government's emphasis on the greening project, the condition of dry climate in northern Shaanxi has been improved obviously, and it has become wet and rainy. However, increased rainfall has led to the frequent occurrence of collapse disasters in the loess region, seriously threatening human lives and properties. Therefore, the structural damage evolution process of loess under the action of a dry-wet cycle should be investigated.

Recent studies on dry-wet cycles have focused on expansive soil and mud-gravel roadbeds. Zhao et al. [3] proposed a constitutive model for simulating the expansioncontraction volume change of expansive soil during a dry-wet cycle. They also defined yield surface to reduce and increase suction and then reported the corresponding change in suction increasing and decreasing yield surface. Li et al. [4] developed a limit analysis method using the Zarka concept for analyzing the mechanical behavior of expansive soil subjected to dry-wet cycles. Burton et al. [5] introduced a comprehensive microstructural analysis of Maryland clay in highly plastic residual soil using mercury intrusion porosimetry test and determined that, similar to the reconstructed microstructures, the compressed microstructures will be erased under saturated (soaking) condition. Kalkan [6] studied the effects of dry-wet cycles on the swelling behavior of modified expansive clay under laboratory conditions. The results 
showed that silica fume reduced the progressive deformation caused by dry-wet cycles on modified expansive clay. Mady and Shein [7] simulated dry-wet cycles through natural conditions, such as "cloudy-sunny-rainfall," and then summarized and analyzed the basic forms and mechanisms of expansive soil roadbed failure. Yang and Xiao [8] discussed the change laws of expansive soil's shear strength under the effect of dry-wet cycles. Other scholars, including Zhang Fangzhi, Zhao Yanlin, Zheng Jun, and Gong Biwei, also analyzed the change laws of the physical and mechanical characteristics of expansive soil under the action of dry-wet cycles from different angles and obtained certain results [9-12]. Gan and Chen [13] conducted a dry-wet cycle test by controlling stress to study microstructure and change in mechanical properties of gravel-encrusted soil. The findings indicated that the dry-wet cycle deformation of soil was caused by dehumidification deformation. Zhang [14] studied the strength and deformation of the gravel soil slopes in the Three Gorges Reservoir area under dry-wet cycle conditions. The results indicated the instability of gravel soil slopes. Cao and Luo [15] studied the change law of gravel soil parameters during the wet-dry cycles. The findings showed that the change in the shear strength of gravel soil exerts considerable impact on the stability of the slope. However, minimal research has been performed to comprehensively analyze structural damage in loess by considering the amplitude and number of dry-wet cycles combined with computed tomography (CT) scanning technology.

In the current study, a large number of dry-wet cycle triaxial compression tests were conducted in Luochuan loess to comprehensively analyze the effects of initial moisture content and the amplitude and number of dry-wet cycles on the strength degradation of loess. From the micro and meso perspectives, CT images and numerical analyses were utilized to perform the meso-structure inspection of crack development and structural degradation inside a loess structure under the action of a dry-wet cycle. The damage evolution law of loess under the action of a dry-wet cycle from the macro and meso perspectives was comprehensively analyzed. The findings can provide a reference for analyzing the damage and degradation of loess during dry-wet cycles and predicting a loess slope disaster.

\section{Test Process}

2.1. Test Materials. Luochuan loess was used as soil sample for laboratory tests in this study. The collected soil samples were subjected to laboratory geotechnical experiments to analyze the physical properties of the loess samples. The physical properties of soil were obtained as listed in Table 1 .

2.2. Test Device. The primary test equipment is composed of the following: (1) an electric heating constant temperature drying oven, (2) a standard unsaturated soil triaxial test system manufactured by the British Government Digital Service (GDS) Company, and (3) a SIEMENS SOMATOM Plus X-ray spiral CT machine. The test equipment is shown in Figure 1.
2.3. Test Plan. The test scheme used Luochuan loess as a background. The crack evolution and strength degradation of loess under repeated dry-wet cycles were investigated.

2.3.1. Dry-Wet Cycle Tests. The in situ soil sample, indoor measurement of moisture content, and data collection indicated that moisture content exhibits a large variation $\left(\omega_{\max }=26 \%, \omega_{\min }=6 \%\right)$. Therefore, dry-wet cycle tests with different times and amplitudes were performed to analyze the changes in the physicomechanical properties of the loess under the action of dry-wet cycles. The drip water and natural air-drying methods were adopted to change the water content of undisturbed soil, and four moisture contents $(10 \%, 15 \%, 20 \%$, and $25 \%)$ were considered for each cycle as control points for dry-wet cycle tests. The quality of the control sample was used to determine the change in water content. When water content reached the control point, a triaxial consolidation undrained shear test was performed. To accelerate test progress, an electric heating constant temperature drying oven was used to dry the soil samples. The prepared soil samples with initial moisture content were dried in a temperature-controlled oven and then moisturized evenly at room temperature using the dripping method to dry the samples. Repeating one dry-wet cycle can yield the subsequent soil samples. Figure 2 shows a dry-wet cycle with a moisture content of $25 \%$ as an example.

Four dry-wet cycle amplitude tests were designed on the basis of the initial moisture content of the soil samples to compare and analyze the tests with different cycle times and amplitudes. Magnitude was determined through the meteorological and hydrological data of Luochuan County and the depth of the steep layer of atmospheric influence. The four dry-wet cycle amplitudes were as follows: $20 \%$ $(5 \%-25 \%), 15 \%(5 \%-20 \%), 10 \%(5 \%-15 \%)$, and $5 \%(5 \%-$ $10 \%)$ for five dry-wet cycles. To reflect the influence of drywet cycle amplitude on the shear strength parameters and reduce test strength, this study considered initial moisture content as the moisture content for the test.

2.3.2. Loess Strength Degradation Test. The majority of the triaxial undisturbed soil samples were prepared and subjected to water distribution methods to prepare multiple groups of triaxial samples with different initial moisture contents. Using conventional triaxial tests, dry-wet cycle tests were performed for each group of soil samples under different confining pressures $\left(\sigma_{3}=50,100,200\right.$, and $\left.300 \mathrm{kPa}\right)$ at $0.2 \mathrm{~mm} / \mathrm{min}$ to control the number of times and amplitudes. The change law of the consolidated undrained (CU) test adopted the method of the $\mathrm{CU}$ shear test.

The GDS triaxial apparatus was used to perform a triaxial test on the undisturbed loess in Luochuan. The diameter and height of the conventional triaxial sample were $3.91 \mathrm{~cm}$ and $8.0 \mathrm{~cm}$, respectively. To study the strength degradation law of the loess under the action of a dry-wet cycle, the stress-strain curve of unsaturated loess under such cycle was analyzed under the control of confining pressure. 
TABLE 1: Experimental statistics of the physical and mechanical properties of the soil samples.

\begin{tabular}{|c|c|c|c|c|c|c|c|c|}
\hline Statistics & $\begin{array}{c}\text { Moisture } \\
\text { content } \\
w(\%)\end{array}$ & $\begin{array}{c}\text { Natural } \\
\text { density } \\
\rho, \mathrm{g} / \mathrm{cm}^{3}\end{array}$ & $\begin{array}{c}\text { Void } \\
\text { ratio } \\
e\end{array}$ & $\begin{array}{c}\text { Granule proportion } \\
\qquad G_{s}\end{array}$ & $\begin{array}{c}\text { Dry density } \\
\rho_{d}, \mathrm{~g} / \mathrm{cm}^{3}\end{array}$ & $\begin{array}{c}\text { Liquid limit } \\
\qquad w_{L}\end{array}$ & $\begin{array}{c}\text { Plastic limit } \\
w_{P}\end{array}$ & $\begin{array}{c}\text { Plasticity index } \\
I_{P}\end{array}$ \\
\hline Maximum value & 21.55 & 1.8 & 1.18 & 2.73 & 1.54 & 32.5 & 20.7 & 11.8 \\
\hline Minimum value & 13.11 & 1.45 & 0.76 & 2.71 & 1.25 & 27.5 & 18.4 & 9.1 \\
\hline Average value & 16.5 & 1.6 & 0.98 & 2.72 & 1.38 & 30.16 & 20.81 & 9.35 \\
\hline
\end{tabular}

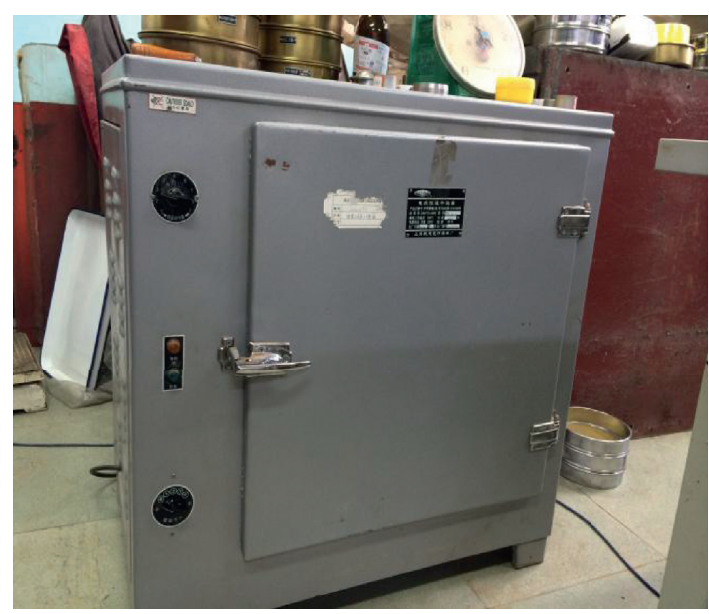

(a)

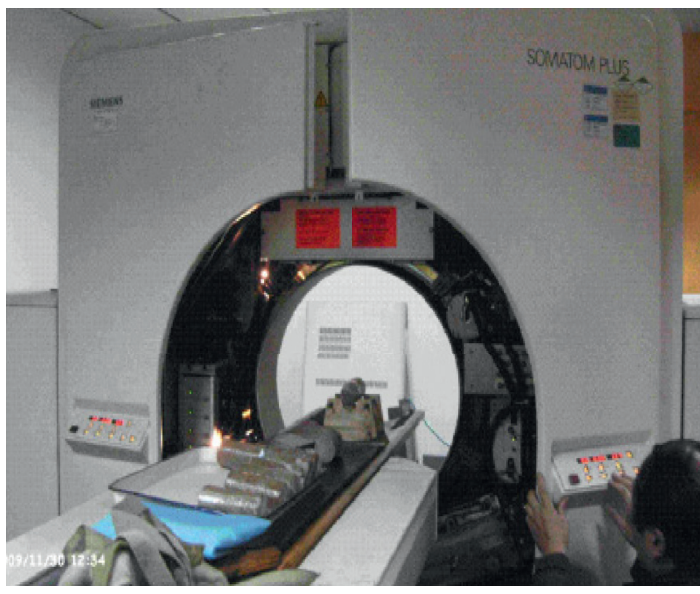

(c)

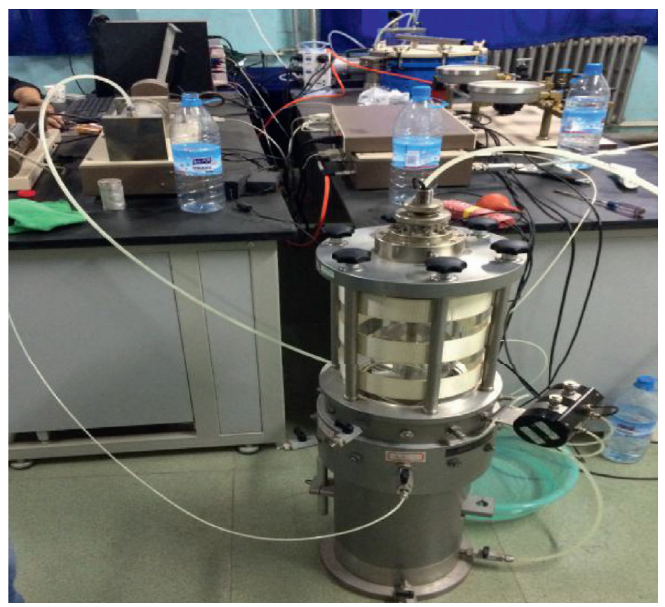

(b)

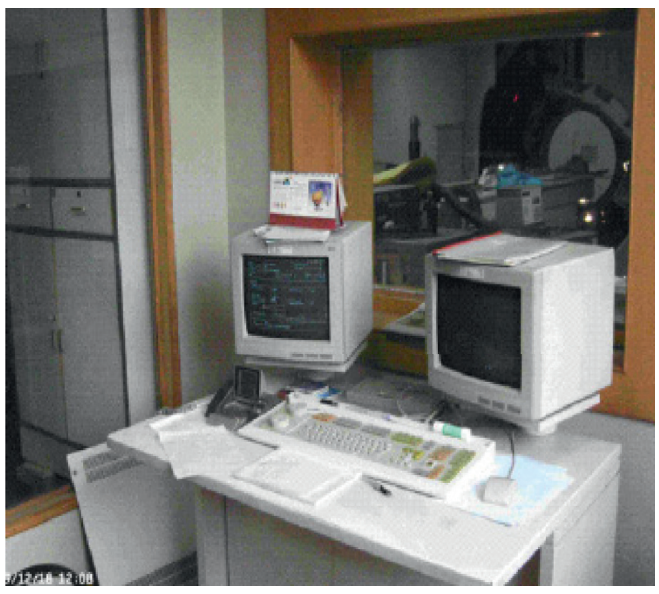

(d)

FIGURE 1: Test equipment. (a) Electric heating constant temperature drying box. (b) GDS three-axis instrument. (c) SIEMENS SOMATOM Plus X-ray spiral CT frame. (d) Computer supporting the CT machine.

2.3.3. Fissure Evolution Test of Loess. Two samples (LC-1 and LC-2) were selected for this test, which was performed to observe the changes in the internal microstructure of the samples after the dry-wet cycles and analyze the effects of different numbers and amplitudes of dry-wet cycles on the structure of loess. The soil samples were Luochuan silty clay. For LC- 1 , density $\rho=1.69 \mathrm{~g} / \mathrm{cm}^{3}$, size $\Phi=61.8 \mathrm{~mm} \times 125 \mathrm{~mm}$, and $\omega=16.5 \%$. For LC- $2, \rho=1.61 \mathrm{~g} / \mathrm{cm}^{3}, \Phi=61.8 \mathrm{~mm} \times 125 \mathrm{~mm}$, and $\omega=16.7 \%$. Then, the water cycle of heating was repeated. The CT-scanned surface was weighed after drying and controlled to maintain the consistency of moisture content with its initial value. The surface of each soil sample was scanned once per cycle ( $1 / 3$ position, $2 / 3$ position). Two layers of the surface were scanned, and the structural changes within the sample were observed. When scanning the surface, the initial scanning position was marked on the soil sample to ensure that the position of the soil sample does not change with each scan, making the scanning comparable. CT information extraction primarily aims to determine the two important indicators of CT (i.e., mean and variance) in the region. The change in CT mean generally reflects the processes of soil damage expansion and destruction. 


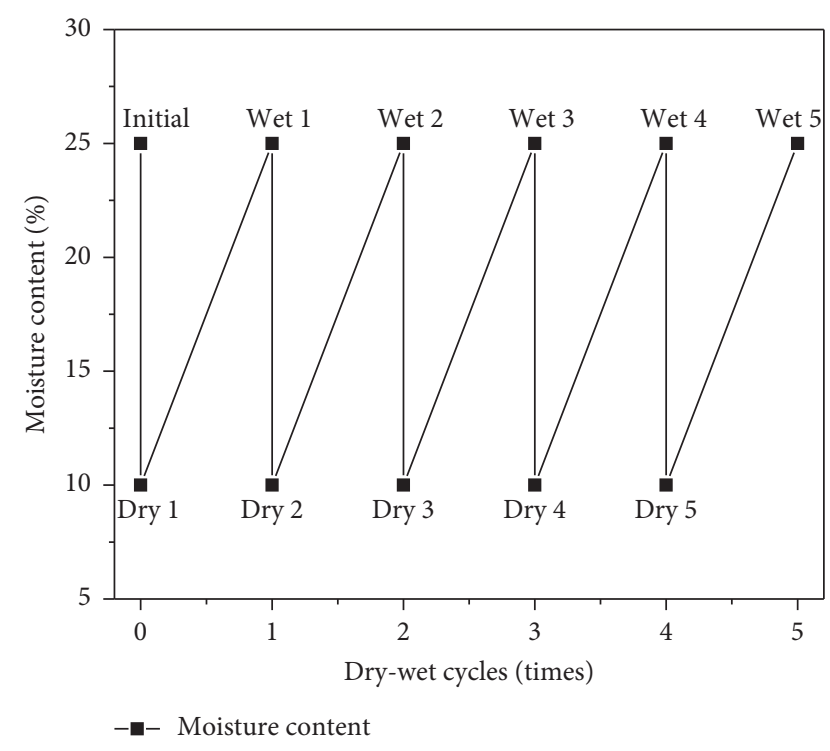

FIgURE 2: Schematic of the dry-wet cycle process.

\section{Analysis of Test Results}

3.1. Analysis of the Damage Evolution Mechanism of Loess Macrostructure due to Dry-Wet Cycles. In this section, drywet cycle tests with different times and amplitudes were performed on triaxial samples. As shown in Figures 3 and 4, changes in the macrocracks on the surface of the Luochuan loess sample were obtained at different amplitudes and times of dry-wet cycles. With an increase in times of dry-wet cycles, surface cracks became evident, the number of cracks increased, and the development degree of the sample intensified. Cracks changed from small to large, short to long, and fine to wide. Structural changes also became increasingly apparent.

The box-counting dimension method was used to analyze variation in the surface cracks of soil samples under the action of a dry-wet cycle from a macro perspective. This method covers the measured area with square grids $(a \times a)$ of different sizes. The total number of square grids required to cover the figure is then calculated on the basis of grid size and fitted using the following formula:

$$
N(a)=A \times a^{-D},
$$

where $a$ is the size of the square grid, $N(a)$ is the corresponding number of square grids, $D$ is the box dimension, and $A$ is the corresponding coefficient.

Yin et al.'s [16] fractal theory in geotechnical engineering was adopted in this study. The relationship between fractal dimension and rock mass coefficient was proposed. In this relationship, the abscissa $L$ represents the joint spacing and the ordinate $N(L)$ denotes the joint strip with spacing greater than L. The logarithms of these variables were then determined, and the regression statistics were arranged to obtain a relevant linear relationship as follows:

$$
N(L) \propto\left(\frac{1}{L}\right)^{D_{f}} \text {. }
$$

The logarithm of equations (3) and (4) is considered to obtain

$$
D=\frac{\lg N(L)}{\lg (1 / L)} .
$$

In the double logarithmic coordinate system, the $(\lg (1 / L), \lg N(L))$ data points are linearly fitted using the least squares method, and the slope of the obtained fitted curve is the fractal dimension $D$ of the surface crack of the sample. In this study, $D$ was used to quantitatively evaluate the change law of soil macrostructure with an increase in the number of dry-wet cycles.

The photos were processed using Adobe Photoshop, and the average crack rate of the sample was calculated using MATLAB to obtain the average value and the fractal dimension of the surface cracks of the sample. The correlation curve between the fractal dimension of the surface cracks of the loess and cycle times under different cycle amplitudes was drawn using cycle times as the abscissa and fractal dimension as the ordinate as shown in Figure 5.

When the volume of the combined water and gravity water in loess clay particles increases, the distance between clay particles wedged by water increases, reducing the magnitude of the force between particles. When the softening degree of the cement is large, the decrease in the friction coefficient and the friction between particles is considerable, increasing the shear strength of the loess sample. Cracks will occur when water pressure between the aggregates of the loess body is greater than the shear strength. When water dries up, the moisture content of the soil sample decreases, the suction of the matrix in the soil sample increases, and the original cracks in the soil sample are closed. Notably, cracks are easily generated in the soil and only temporarily close but will not disappear due to the unrecoverable tensile strength of the soil. New cracks will occur when the tensile force caused by the hydraulic gradient of the dehumidification process is greater than the tensile strength of the soil. Therefore, the total number of cracks increases during a dry-wet cycle. The original cracks will occur again during rehumidification. The hydraulic gradient required for these cracks to occur is smaller than that in the previous cycle due to the increase in the number of cracks, and the tensile stress generated during the dry-wet cycle is gradually reduced. Consequently, the amplitude of cracks generated during the dry-wet cycle is reduced. Cracks stop developing and expanding when the tensile stress generated by the hydraulic gradient due to the dry-wet cycle is less than the tensile strength of the soil.

\subsection{Effect of Dry-Wet Cycles on the Strength of Loess}

3.2.1. Influence of the Number of Dry-Wet Cycles on the Strength of Loess. Figures 6-9 display the partial stressstrain curves of the static triaxial tests on undisturbed loess under different dry-wet cycles and confining pressures, where $q_{0}$ represents the stress value $\left(\sigma_{1}-\sigma_{3}\right)$ of the undisturbed loess at a certain strain $\varepsilon$. 


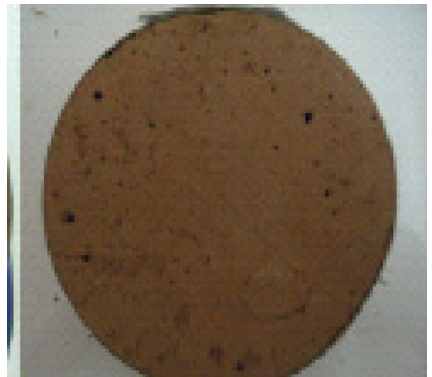

(a)

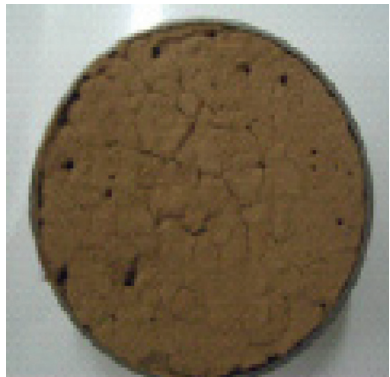

(b)

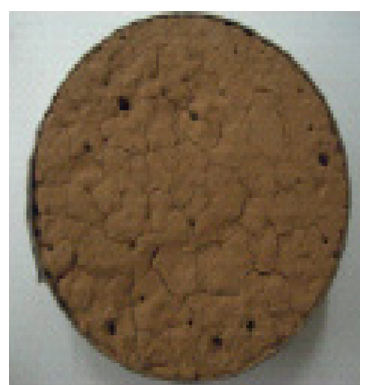

(c)

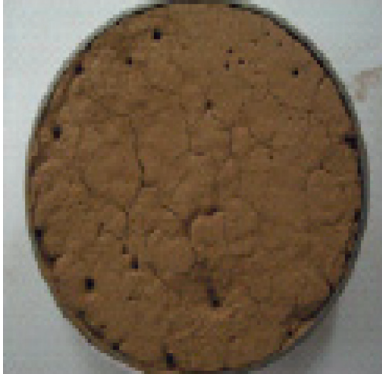

(d)

FIGURE 3: Surface characteristics of Luochuan loess macrostructure during a dry-wet cycle when cycle amplitude $(\Delta w)=10 \%$. (a). Initial state. (b) One cycle. (c). Three cycles. (d). Five cycles.

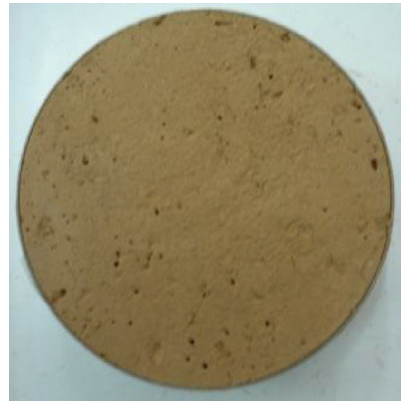

(a)

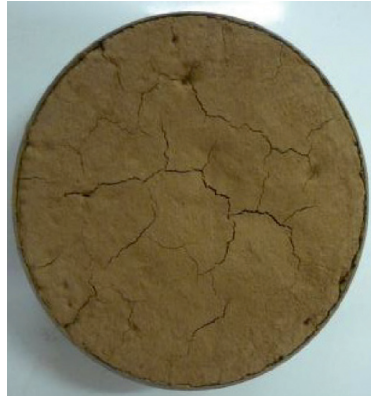

(b)

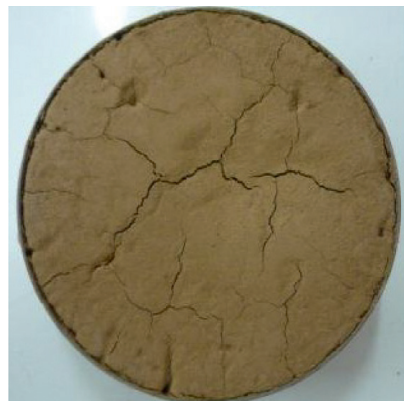

(c)

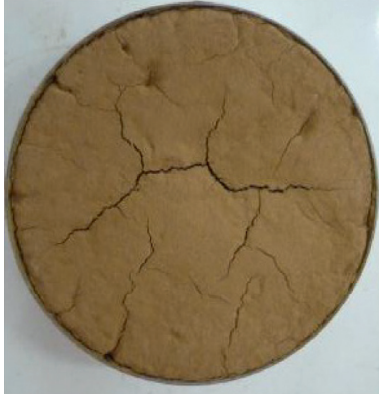

(d)

FIGURE 4: Surface characteristics of Luochuan loess macrostructure during a dry-wet cycle when $\Delta w=5 \%$. (a). Initial state. (b). One cycle. (c). Three cycles. (d). Five cycles.

The stress-strain curves of the undisturbed loess samples under different cycle times considerably vary. Under the same axial strain, the stress value of undisturbed loess is higher than that of the loess sample after a dry-wet cycle, implying that dry-wet cycles exert a degrading effect on the strength of loess. When confining pressure and water content are low, the difference in the principal stress of undisturbed loess gradually decreases under the same axis, and the change amplitude decreases as the number of drywet cycles increases. Typical structural soils exhibit a certain degree of shear shrinkage. When the confining pressure is less than the structural strength, the stress-strain curve demonstrates a softened peak point; the corresponding structural strength plays a major role. The first stage of deformation is approximated. During the linear elastic stage, the loess body exhibits a certain amount of shear shrinkage. During the second stage of deformation, the structural strength of the loess body begins to deteriorate. Slips occur between loess particles, the structure is damaged, and dilatancy occurs. The stress-strain curve displays a nonlinear increasing trend. The third stage is called the stage of stable equilibrium. During this stage, shrinkage and dilatancy complement each other to attain balance, volume change stabilizes, and the stress-strain curve tends to decline gently and slowly. As the number of dry-wet cycle increases, the stress-strain curve exhibits no peak point, the shape of the curve changes from weakly softened to hardened, and the

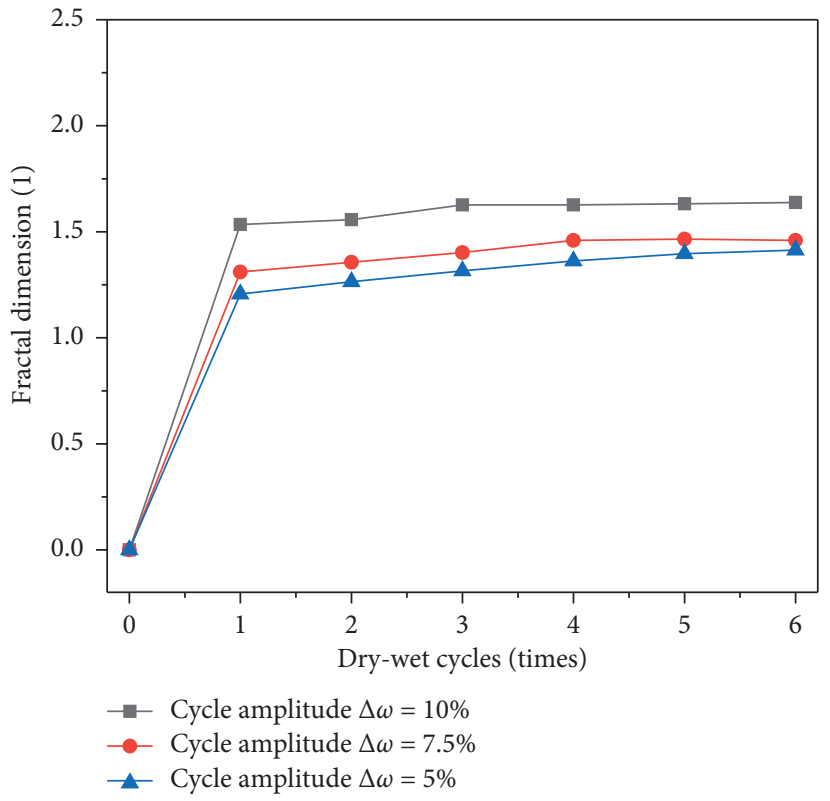

Figure 5: Curves of the fractal dimension of the fissures on the surface of the loess samples, number of cycles, and amplitude.

amplitude of the hardened curve becomes increasingly evident. The position of the strain curve decreases, the change in the principal stress difference follows a decreasing trend, 


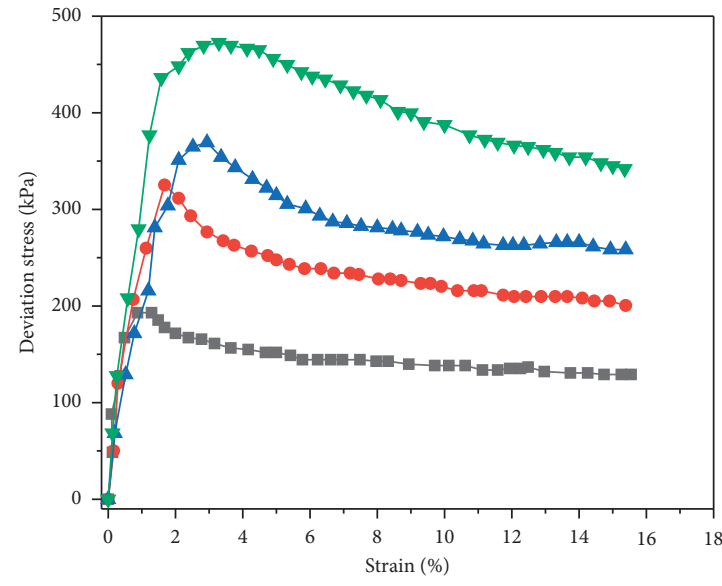

- Confining pressure $50 \mathrm{kPa} \_$Confining pressure $200 \mathrm{kPa}$ $\longrightarrow$ Confining pressure $100 \mathrm{kPa} \longrightarrow$ Confining pressure $300 \mathrm{kPa}$

(a)

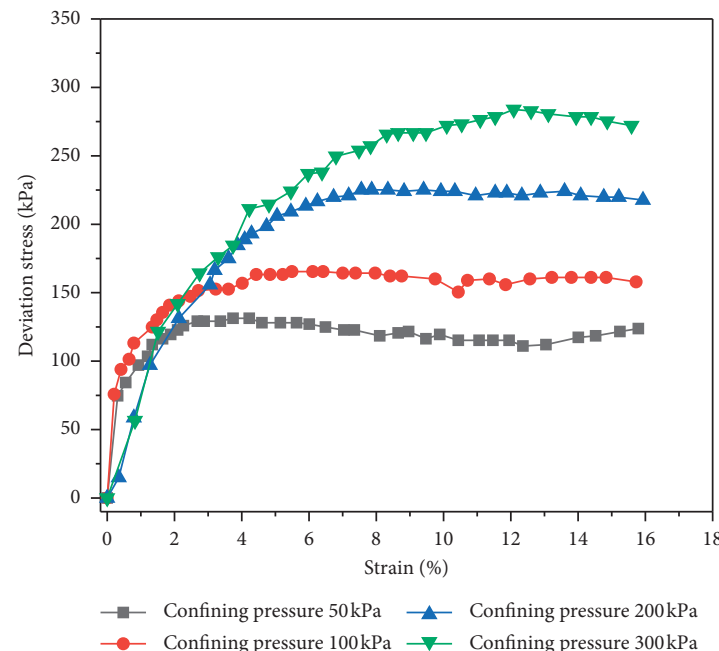

(c)

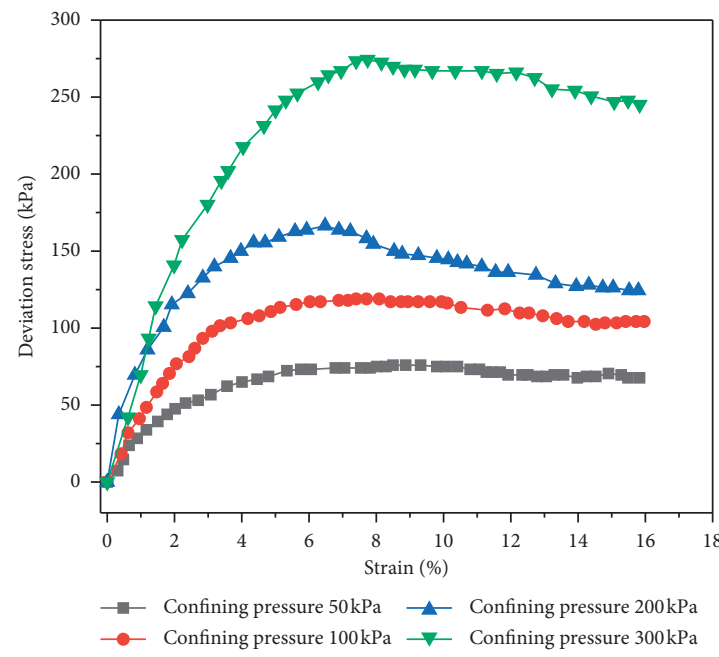

(e)

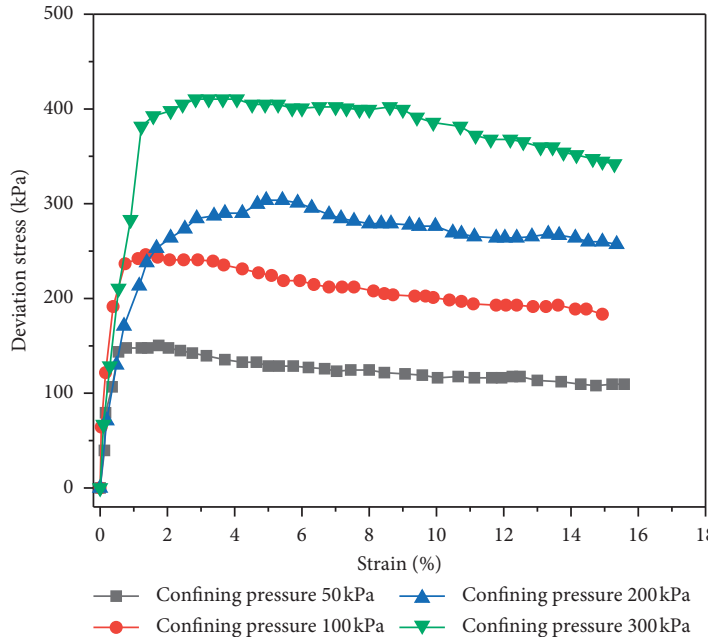

(b)

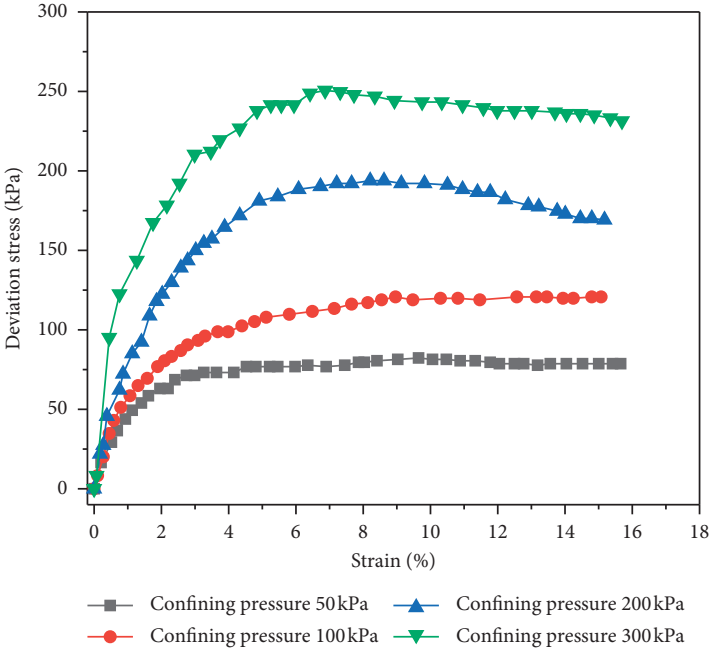

(d)

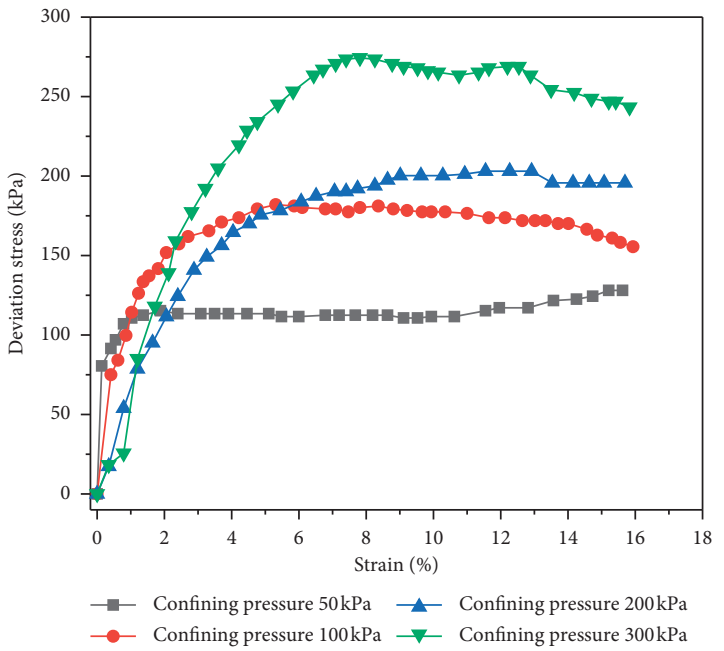

(f)

Figure 6: Stress-strain curves of the samples with an initial water content of $w=25 \%$ for different numbers of cycles. Moisture content $w=25 \%$ for (a) zero cycles. (b) one cycle, (c) two cycles, (d) three cycles, (e) four cycles, and (f) five cycles. 


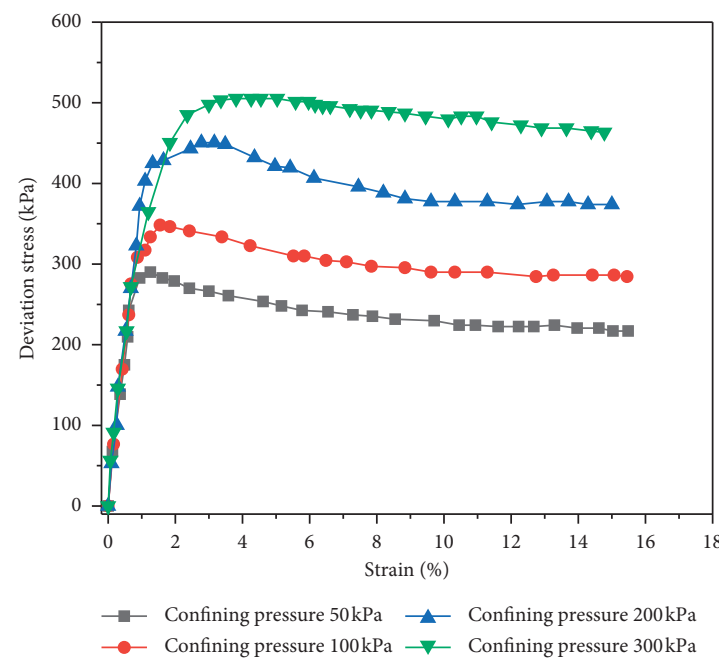

(a)

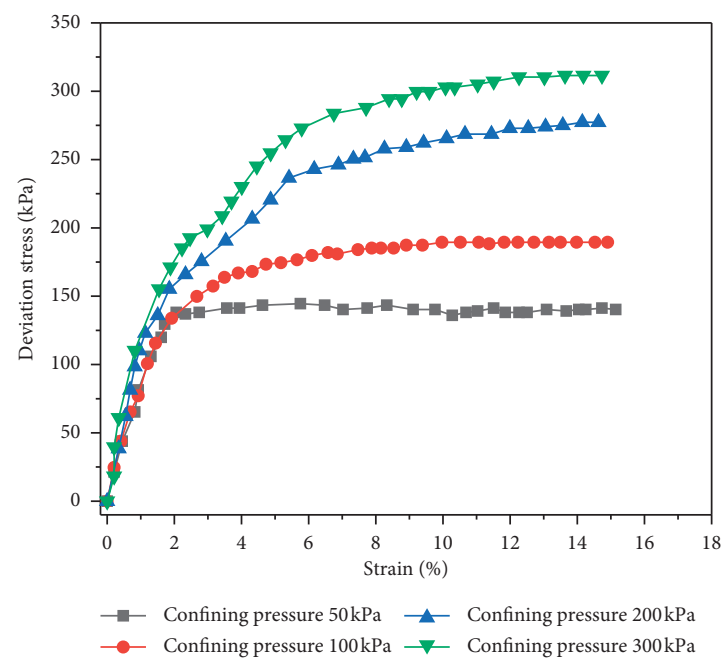

(c)

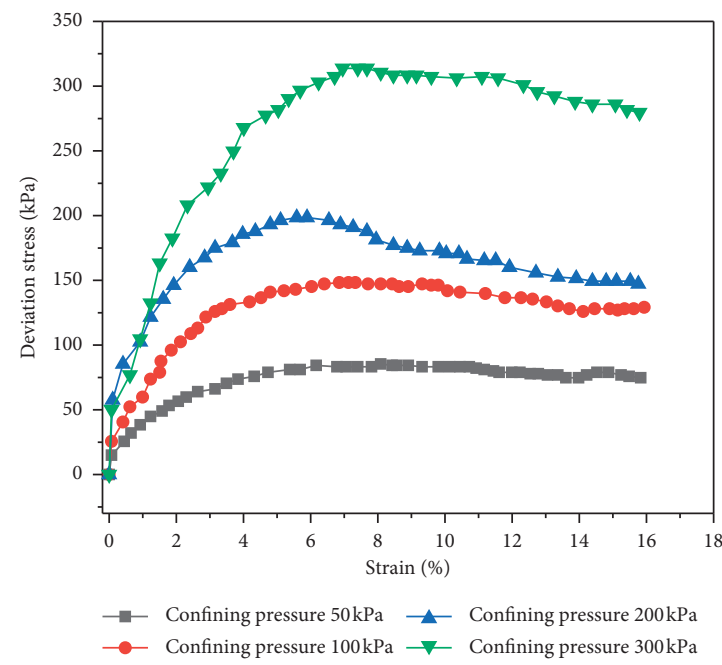

(e)

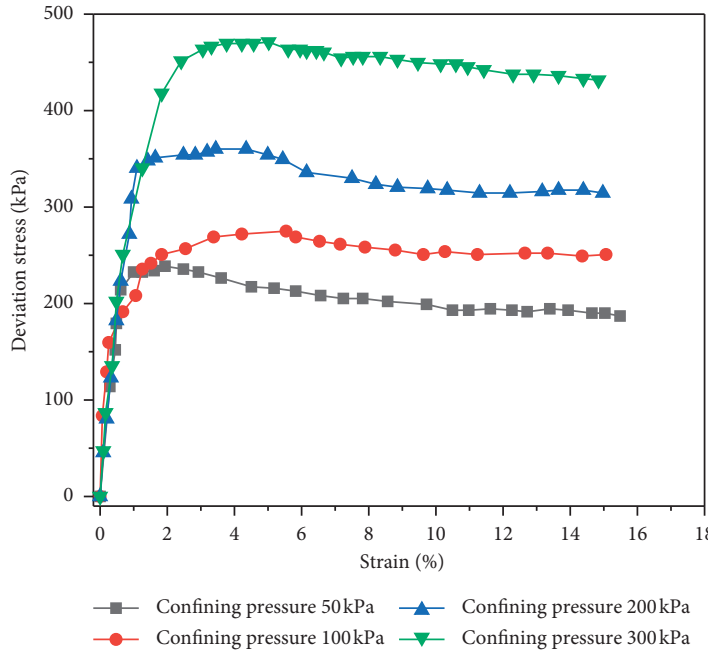

(b)

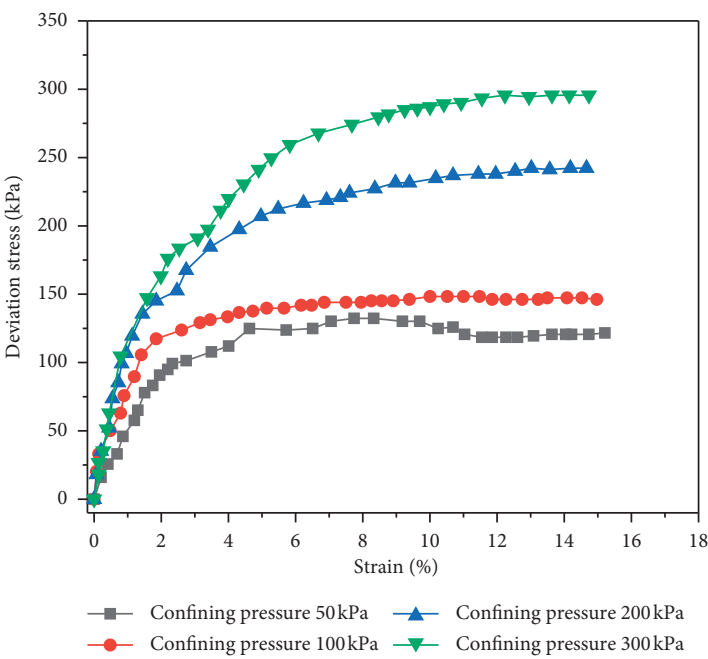

(d)

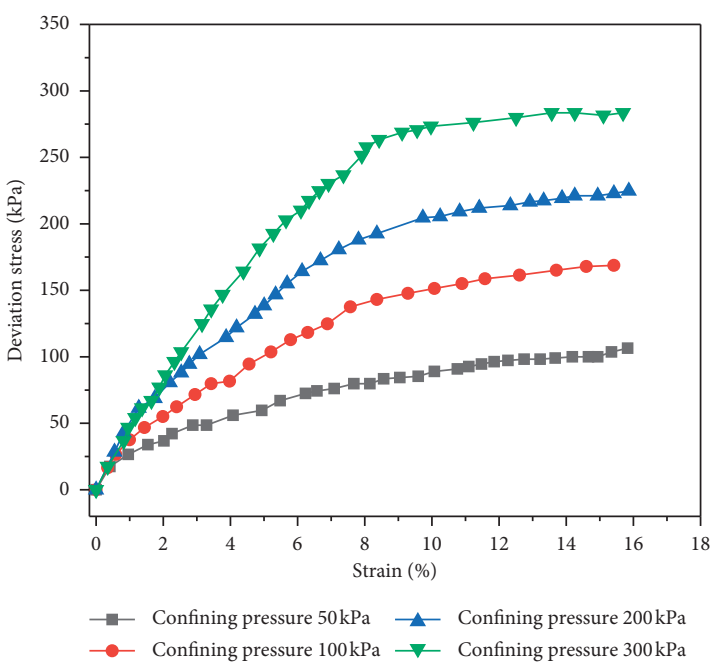

(f)

FiguRE 7: Stress-strain curves of the samples with an initial water content of $w=20 \%$ for different numbers of cycles. Moisture content $w=20 \%$ for (a) zero cycles, (b) one cycle, (c) two cycles, (d) three cycles, (e) four cycles, and (f) five cycles. 


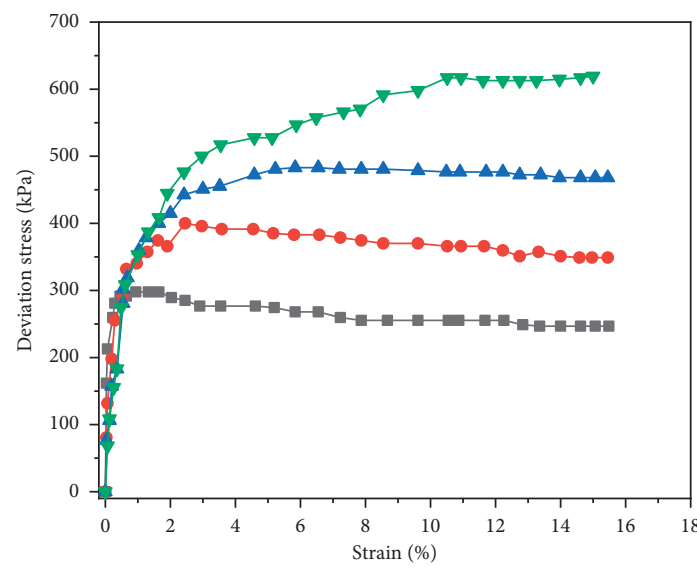

- Confining pressure $50 \mathrm{kPa} \_$Confining pressure $200 \mathrm{kPa}$ - Confining pressure $100 \mathrm{kPa} \longrightarrow$ Confining pressure $300 \mathrm{kPa}$

(a)

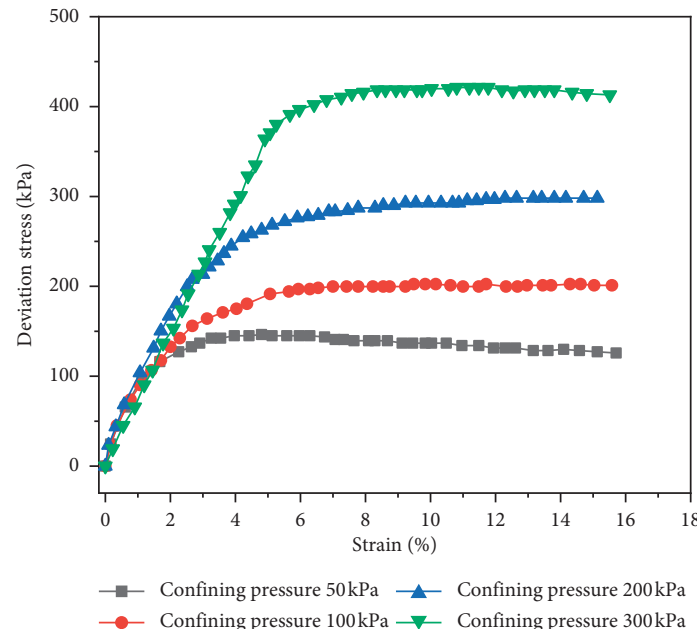

(c)

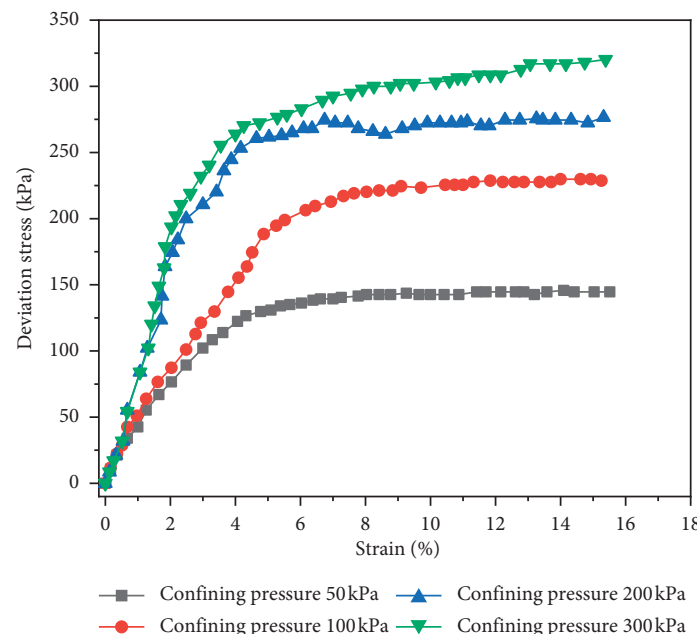

(e)

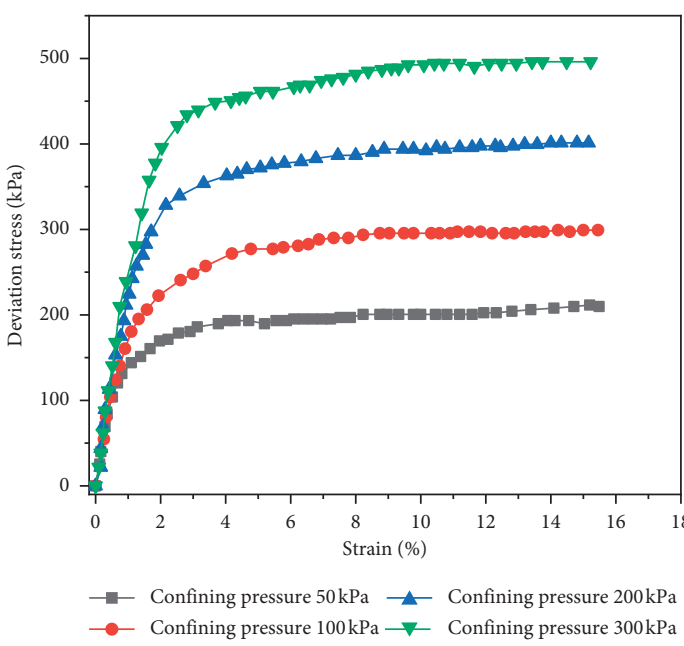

(b)

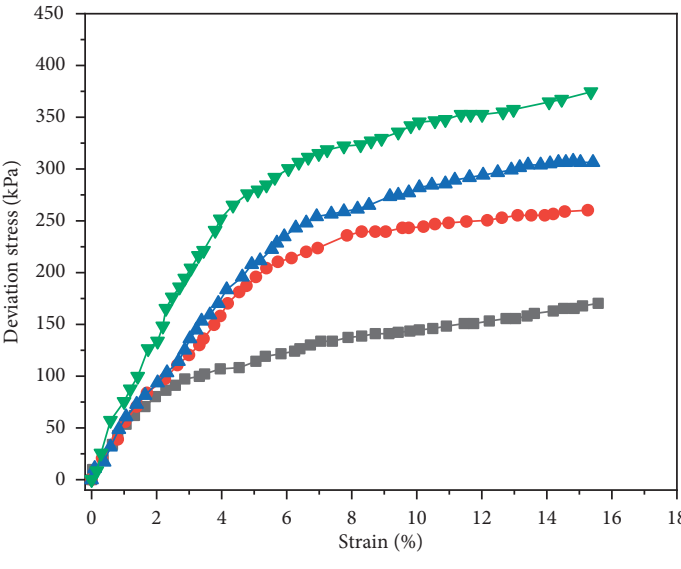

$\longrightarrow$ Confining pressure $50 \mathrm{kPa} \longrightarrow$ Confining pressure $200 \mathrm{kPa}$

- Confining pressure $100 \mathrm{kPa} \rightarrow-$ Confining pressure $300 \mathrm{kPa}$

(d)

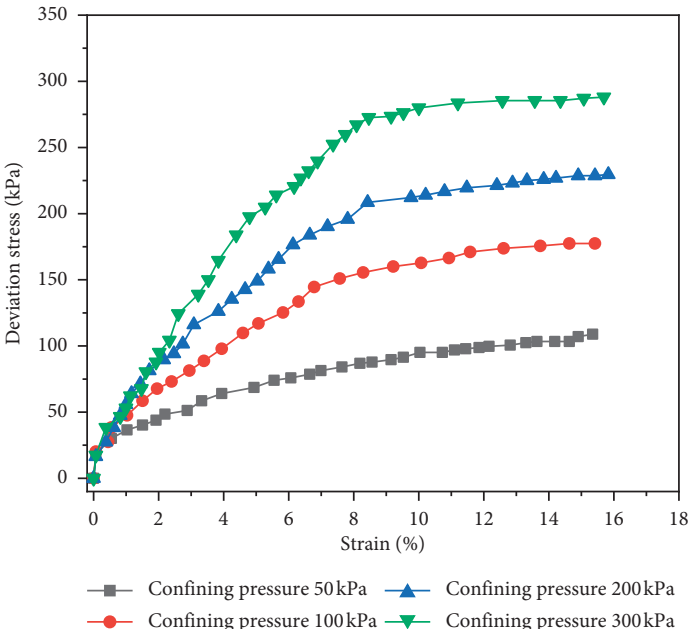

(f)

FIgURE 8: Stress-strain curves of the samples with an initial water content of $w=15 \%$ for different numbers of cycles. Moisture content $w=15 \%$ for (a) zero cycles, (b) one cycle, (c) two cycles, (d) three cycles, (e) four cycles, and (f) five cycles.

indicating that the strength of loess is gradually deteriorating. The primary reason for this phenomenon is that loess has vertical joints, its structure is relatively strong, and its permeability is good. Therefore, as the number of dry-wet cycle increases, soil skeleton changes irrecoverably, seriously reducing the strength of the original soil structure, and 


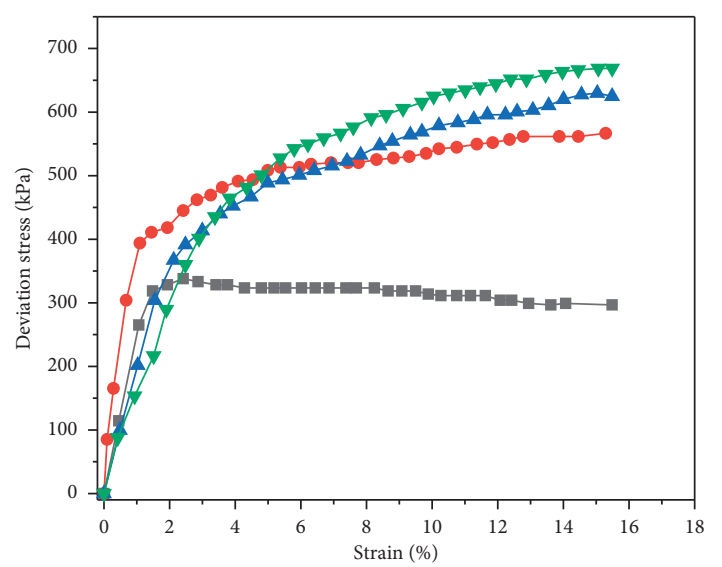

$\rightarrow$ Confining pressure $50 \mathrm{kPa} \longrightarrow$ Confining pressure $200 \mathrm{kPa}$ $\longrightarrow$ Confining pressure $100 \mathrm{kPa} \longrightarrow$ Confining pressure $300 \mathrm{kPa}$

(a)

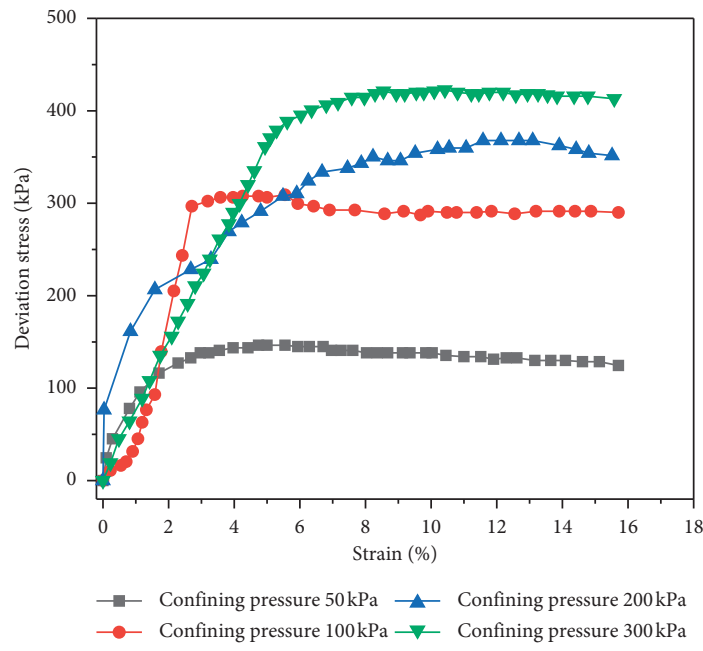

(c)

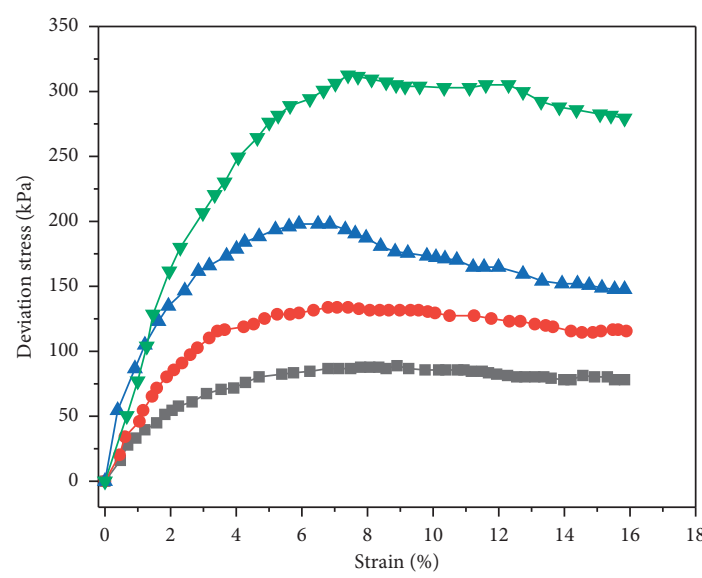

$\rightarrow-$ Confining pressure $50 \mathrm{kPa} \longrightarrow$ Confining pressure $200 \mathrm{kPa}$ $\longrightarrow$ Confining pressure $100 \mathrm{kPa} \longrightarrow$ Confining pressure $300 \mathrm{kPa}$

(e)

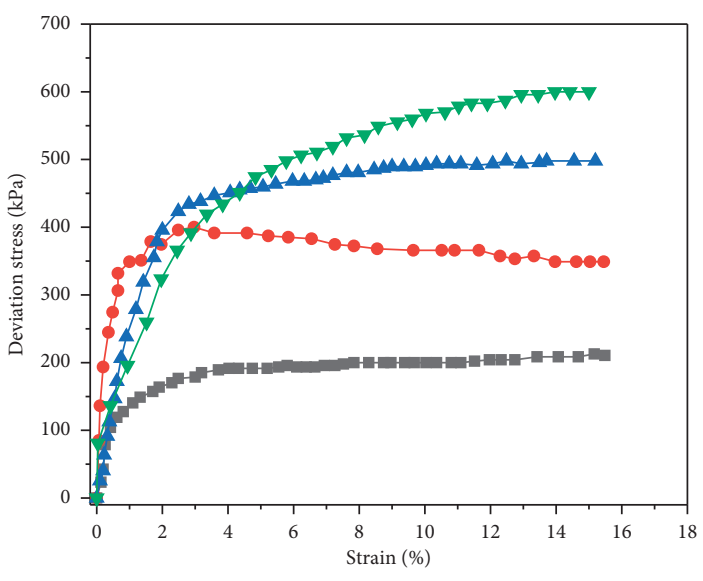

$\rightarrow$ Confining pressure $50 \mathrm{kPa} \_$Confining pressure $200 \mathrm{kPa}$ - Confining pressure $100 \mathrm{kPa} \longrightarrow$ Confining pressure $300 \mathrm{kPa}$

(b)

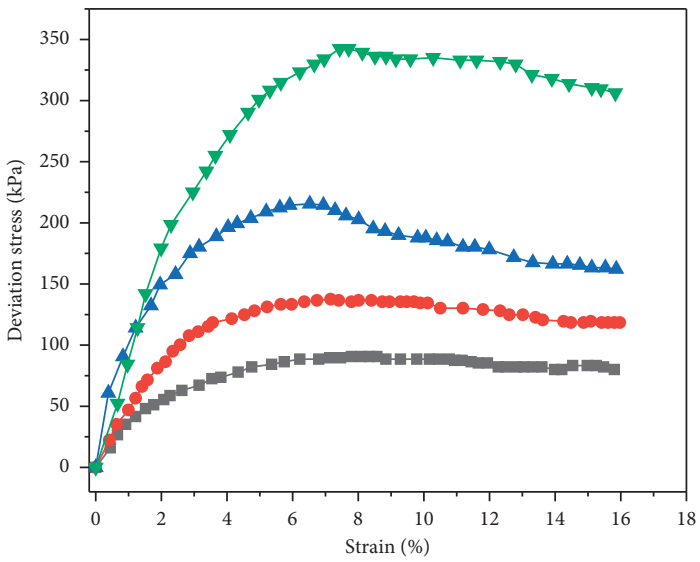

- Confining pressure $50 \mathrm{kPa} \longrightarrow$ Confining pressure $200 \mathrm{kPa}$

- Confining pressure $100 \mathrm{kPa} \longrightarrow$ Confining pressure $300 \mathrm{kPa}$

(d)

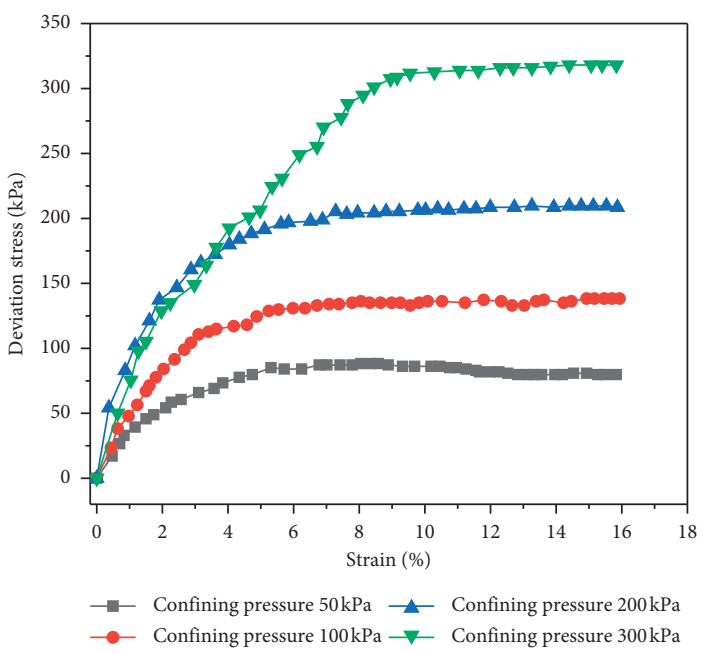

(f)

Figure 9: Stress-strain curves of the samples with an initial water content of $w=10 \%$ for different numbers of cycles. Moisture content $w=10 \%$ for (a) zero cycles, (b) one cycle, (c) two cycles, (d) three cycles, (e) four cycles, and (f) five cycles. 


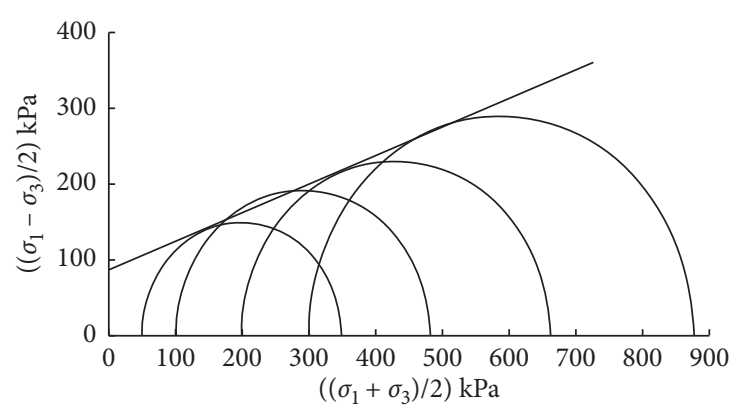

(a)

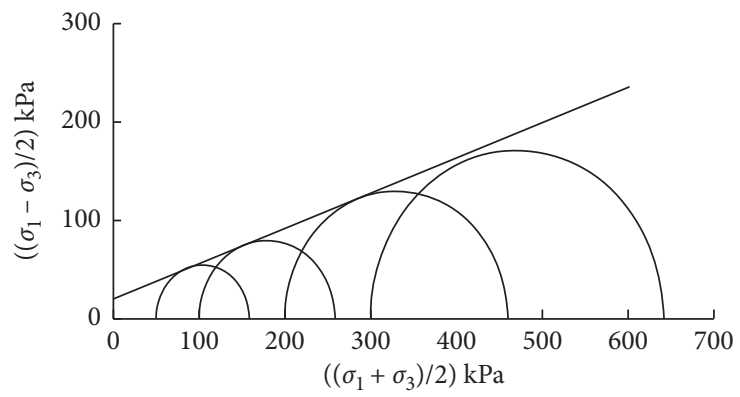

(c)

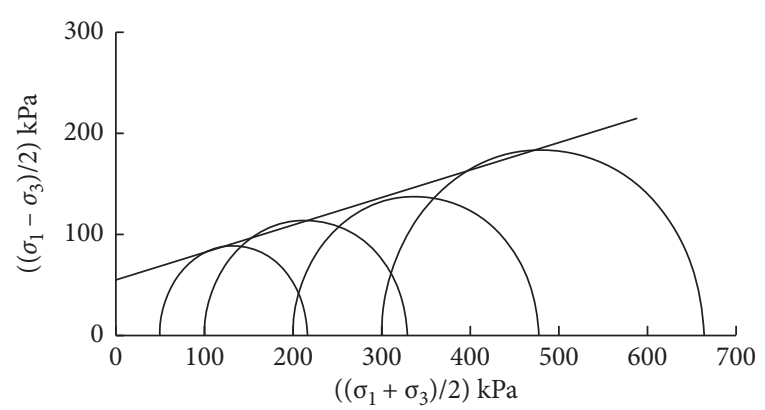

(b)

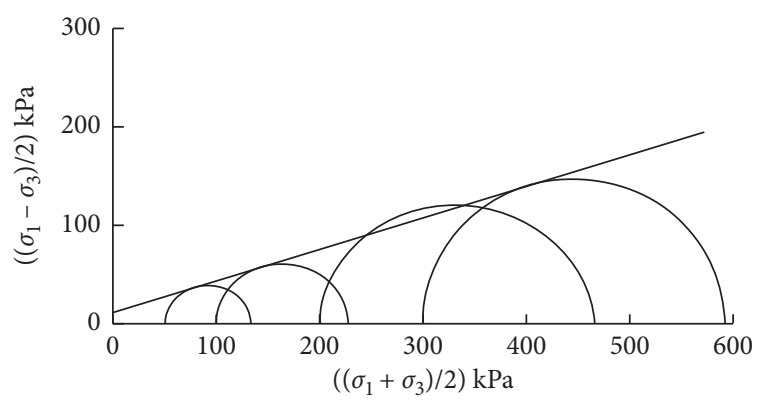

(d)

Figure 10: Mohr circles and strength envelopes of the samples with 25\% initial moisture content at different numbers of cycles. Mohr circle and strength envelope (a) during the initial state, (b) in a dry-wet cycle, (c) in three dry-wet cycles, and (d) in five dry-wet cycles.

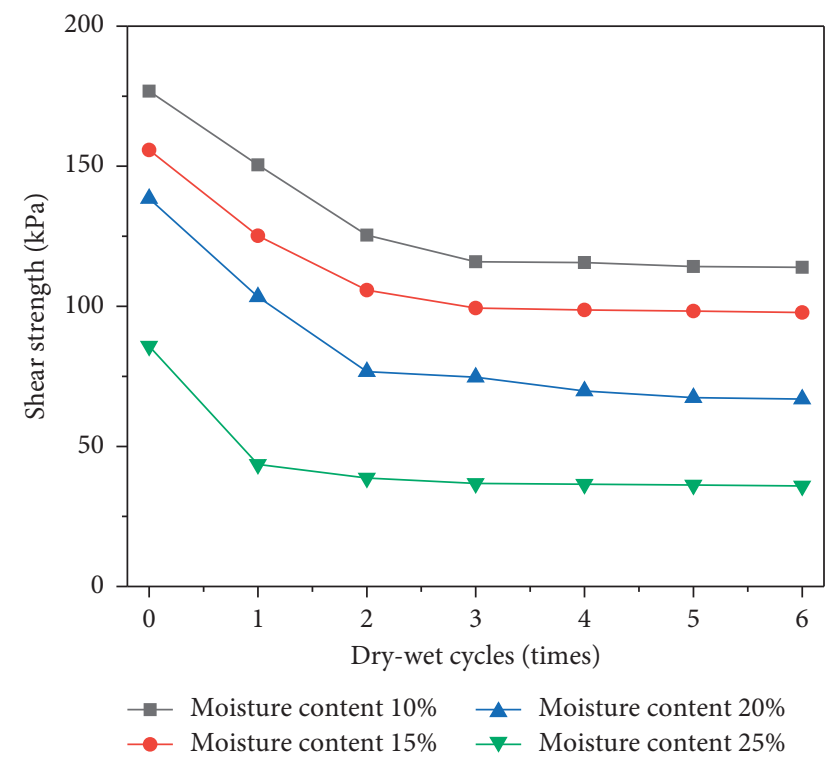

FIGURE 11: Relationship between shear strength $\tau$ and cycle times of the Luochuan soil samples with different water contents when $\Delta w=10 \%$.

eventually the structural strength of loess wanes. In summary, the effect of dry-wet cycles is the major factor that decreases the strength of undisturbed loess.

(1) Effect of the Number of Dry-Wet Cycles on Loess Shear Strength $\tau$. Using 25\% water content as an example, the peak point of the stress-strain curve is set as the failure point.
When no peak point is observed, a principal stress difference of $15 \%$ axial strain is adopted as the failure point. With normal stress as the abscissa, $\left(\sigma_{1 f}+\sigma_{3 f}\right) / 2$ as the center of the circle, shear stress as the ordinate, and $\left(\sigma_{1 f}+\sigma_{3 f}\right) / 2$ as the radius ( $\mathrm{f}$ is the failure state), the Mohr stress circle is plotted on the $\tau-\sigma$ stress plane. Similarly, the failure under different confining pressures is plotted. The envelope of the stress circle is illustrated in Figure 10.

The total shear strength of undisturbed loess with different water contents is obtained from this. The curves of the shear strength of the loess sample under different dry-wet cycle conditions are shown in Figure 11.

Figure 11 shows that, under the same number of dry-wet cycles, the moisture content of the soil samples gradually increases, their shear strength decreases, and the decreasing range changes. An apparent phenomenon is also observed in the figure. Shear strength decreases the most during the first dry-wet cycle. Shear strength tends to be stable from the second to fifth cycles. Evidently, the slopes of the shear strength lines with water contents of $10 \%, 15 \%, 20 \%$, and $25 \%$ are relatively close. However, the slopes of the shear strength lines with water contents of $15 \%$ to $20 \%$ change significantly, indicating that the cohesion and internal friction angle have been changed considerably because loess itself exhibits a certain structural strength. Under the influence of atmospheric stress, unsaturated loess repeatedly swells and shrinks, soil cracks, the original structure is destroyed, cementation capacity between soil particles is weakened, and structural force gradually disappears, making wedging with a water-solvent film easy. In addition, van der Waals force is generated inside the soil. Under the action of 


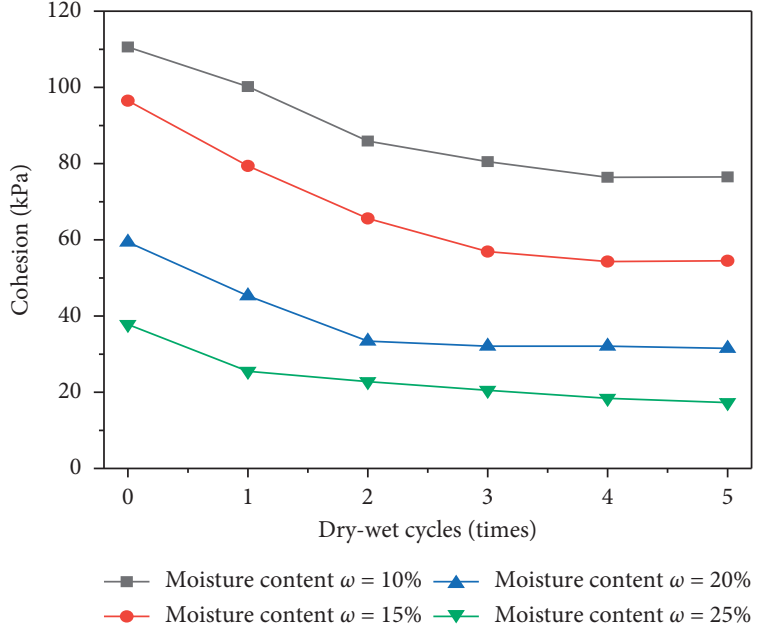

(a)

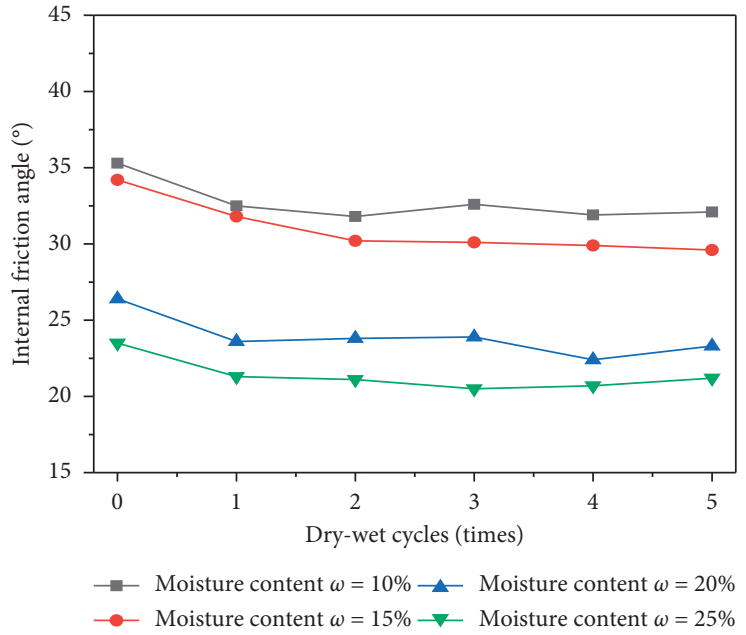

(b)

FiguRE 12: Relationship between the strength parameters of the soil samples with different moisture contents and numbers of cycles in Luochuan. (a) Relationship between cohesion $(c)$ and number of cycles $(N)$. (b) Relationship between friction angle $(\varphi)$ and number of cycles $(N)$.

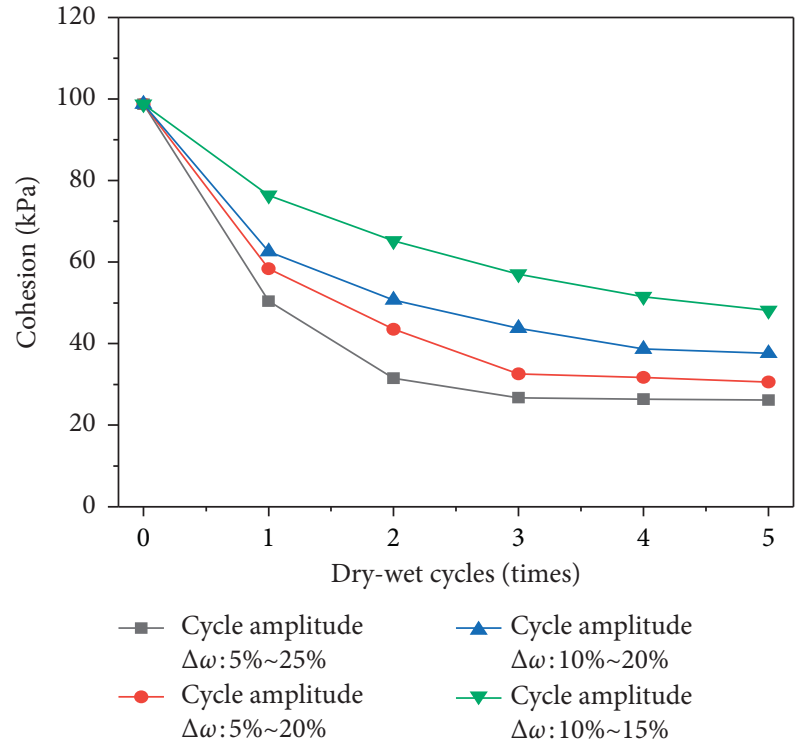

(a)

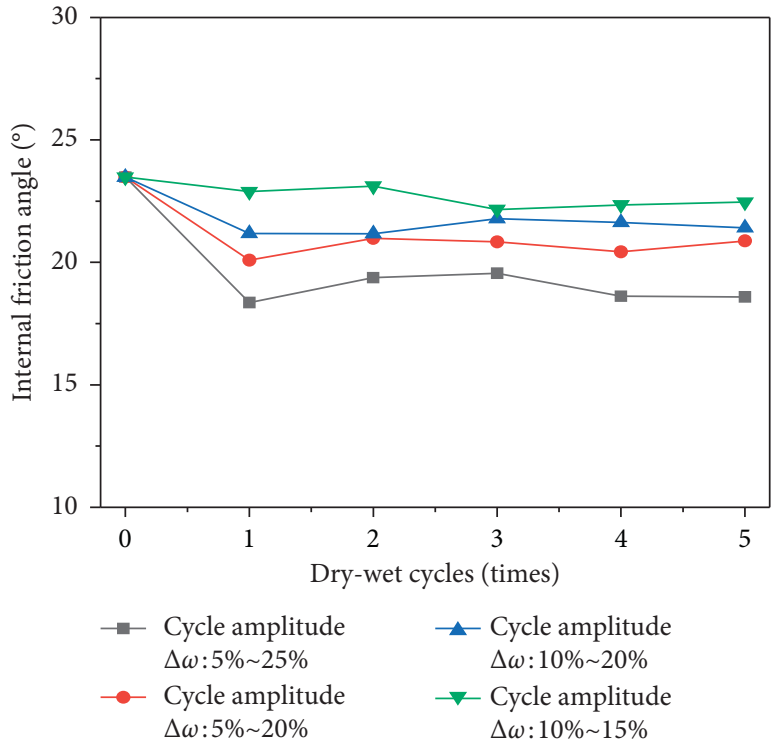

(b)

FIGURE 13: Relationship between the shear strength indexes of different dry-wet cycle amplitudes and $\Delta w$ of the Luochuan soil samples. (a) Relationship curve between the cohesion and cyclic amplitude of the soil samples under different dry-wet cycle amplitudes. (b) Relationship curve between the friction angle and cycle amplitude of the soil samples under different amplitudes of dry-wet cycles.

this force, soil particles gradually aggregate, gradually decreasing the clay content of the soil and increasing porosity. Permeability is enhanced, plasticity is reduced, and the coupling force between soil particles is reduced. Consequently, the skeleton of the soil is changed, its structural strength is reduced, and its shear strength is reduced accordingly. Structural strength is an important component of the shear strength of the soil samples. With a continuous increase in the number of dry-wet cycles, structural strength gradually wanes, and the shear strength of the soil samples stabilizes. In actual engineering, the expansion and contraction cracks generated by the soil are mostly caused by the drying and shrinking processes, and the extent will increase as pressure on the soil decreases and cycle amplitude increases. During a dry-wet cycle, the change law of the shear strength index of the soil varies depending on the pressure of the soil and the number and magnitude of cycles. The subsequent 
section analyzes the effects of the different numbers of dry-wet cycles on two strength indicators: cohesion and internal friction angle.

(2) Effect of the Number of Dry-Wet Cycles on the Shear Strength Index of Loess. Here, $C=c^{\prime}+\left(u_{a}-u_{w}\right) \tan \phi^{b}$ and $\phi^{\prime}$ are regarded as the shear strength indicators. The relationship curve between the loess shear strength indicators and the number of dry-wet cycles is obtained as shown in Figure 12.

Figure 12(a) shows the change curve of the cohesion of the loess samples and the number of dry-wet cycles under different moisture contents. As shown in the figure, the moisture content of loess increases and its cohesion decreases when the number of dry-wet cycles is constant. The change in cohesion of loess decreases significantly when the plastic limit moisture content is reached. When moisture content is $10 \%$, the change in cohesive force is reduced from $110.6 \mathrm{kPa}$ to $76.5 \mathrm{kPa}$. When moisture content is $25 \%$, the change in cohesive force is reduced from $37.8 \mathrm{kPa}$ to $17.3 \mathrm{kPa}$. After the dry-wet cycles of the loess, the change in cohesion is smaller when the moisture content is larger. This result shows that moisture content affects the degradation of loess cohesion via dry-wet cycles. However, considering only the effect of dry-wet cycles, moisture content exerts a significant degradation effect on the cohesion of soil samples. A dry-wet cycle is mostly caused by the physical weathering and chemical erosion of moisture. Given that the cohesive force is produced by the combination of cementation between soil particles and the combination of the water film and gravitational effect of the water molecules during drywet cycles, the cementitious substances of the soil particles within a soil sample exhibit a strengthening cohesive force. Cohesion is weakened. As the number of dry-wet cycles increases, the cohesive force value continues to decrease. Its value decreases the most during one or two cycles, and the decrease becomes stable thereafter. Figure 12(b) shows the relationship between the internal friction angle of loess and the number of dry-wet cycles. The internal friction angle $(\varphi)$ is insignificantly affected by dry-wet cycles, but moisture content controls the value of the internal friction angle. Moisture content decreases from the initial value of 26.4 to 23.6 with a water content of $20 \%$, and the decrease range is $9.8 \%$. However, as the number of dry-wet cycles increases, the change is inevident and fluctuates up and down, indicating that the friction angle is attenuated during the initial stage of a dry-wet cycle. The attenuation range is small, and its value becomes basically stable with an increase in the number of dry-wetting cycles. In summary, soil moisture, pore distribution, and the arrangement of soil particles undergo considerable changes due to the initial dry-wet cycle. Thereafter, the change becomes inevident as the number of dry-wet cycles increases.

3.2.2. Effect of the Amplitude of Dry-Wet Cycles on the Strength of Loess. A direct shear test exhibits certain comparability with the triaxial shear sample; thus, this section of the soil sample undergoes consolidated direct shear test. For the direct shear test, a consolidated fast shear test was performed using a ZJ strain-controlled direct shear instrument produced by Nanjing Soil Instrument Factory, with a shear rate of $0.15 \mathrm{~mm} / \mathrm{min}$. For soil samples with varying moisture contents, different dry-wet cycle amplitude tests were performed according to Section 3.2. When the moisture content of the soil sample reached the control point, consolidated fast shear test was performed under four vertical pressures $(50,100,200$, and $300 \mathrm{kPa})$. The results of the consolidated fast shear test are presented in Figure 13.

As shown in Figure 13, cohesive force decreases and the internal friction angle remains substantially unchanged as $\Delta w$ increases at the same number of cycles. The strength of Luochuan loess is primarily controlled by the cohesive force of the shear strength index, which indicates that the number of times of strength stabilization and the magnitude of strength stability are also related to $\Delta w$. For example, when the cycle amplitude $\Delta w=10 \% \sim 15 \%$, the strength will achieve stability within five dry-wet cycles; when the cycle amplitude $\Delta w=5 \% \sim 25 \%$, the strength will reach a stable value within three dry-wet cycles because structural loess is sensitive to water. The presence and reduction of water exert a certain effect on the interaction between loess particles and water, including hydrogen bonding and the hydration of exchangeable cations. Dialysis, electrostatic and van der Waals forces, and matrix suction will change the strength of soil. Loess exhibits a certain structure primarily due to the presence of cementing mineral components in loess. These mineral components gradually dissolve under the physical action of water, weakening the connection between soil particles, reducing compactness, and surrounding the colloid. The thickening of the water film promotes the weakening of the structure and strength of the soil, causing deformation and damage. During the unsaturated state of loess, water evaporation promotes the deformation of clay particles and the structure of clay oxide. The content of the adsorbed water in the loess also decreases, the soil shrinks, and volume decreases. During this shrinking process, the soil particles aggregate again, causing a slight change in the internal friction angle. The cohesive force is considerably reduced due to the softening of the water. Whether the friction angle in the soil increases or decreases generally depends on whether the interaction between soil particles under the action of dry-wet cycles causes the internal friction angle of the soil to increase or decrease further. If it is significantly larger than the decrease, then the friction angle in the soil generally increases; otherwise, it decreases. Therefore, the influence of dry-wet cycles on the internal friction angle of the loess samples does not follow a regular trend.

The effect of a dry-wet cycle is attributed to the repeated loading and unloading of matrix suction in soil, resulting in an irreversible damage process to the internal structure of soil. The test results indicated that the effect of the dry-wet cycle of loess is closely related to the control parameters of the cycle. Therefore, under the action of a dry-wet cycle, the control of a series of related parameters, such as soil body and cycle order, should be strengthened to explore and discuss the attenuation law of the effect of dry-wet cycles on loess, particularly the change law of intensity. 


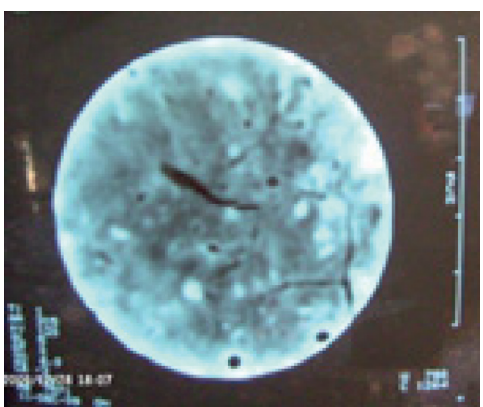

(a)

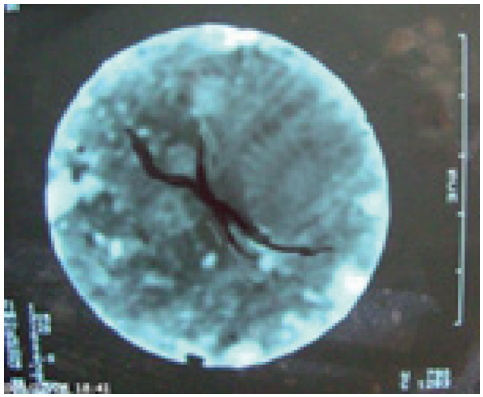

(d)

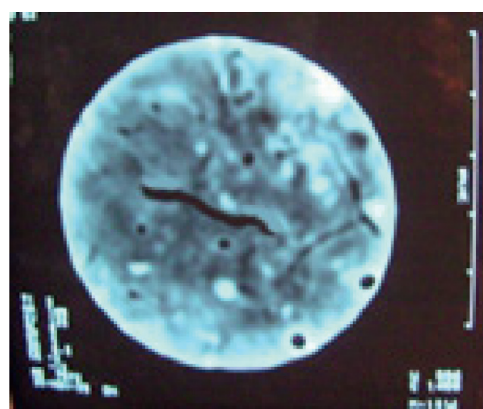

(b)

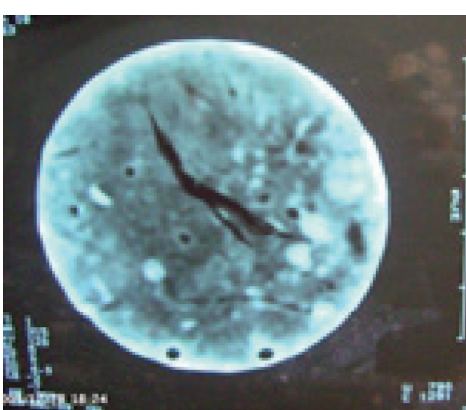

(c)

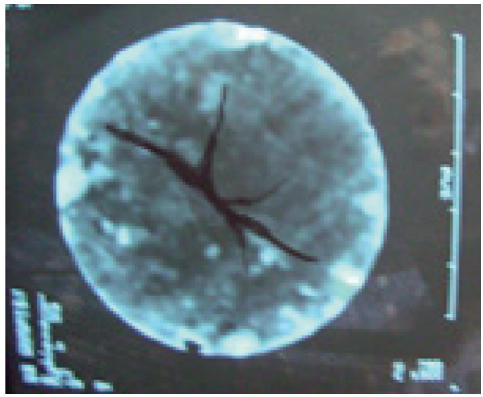

(e)

Figure 14: CT images of the $a$ section position of the LC-1 sample with cycle amplitude $\Delta w=10 \%$. (a) Zero cycles. (b) One cycle. (c) Two cycles. (d) Four cycles. (e) Six cycles.

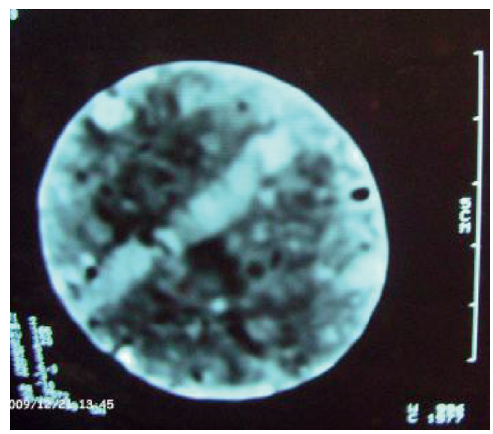

(a)

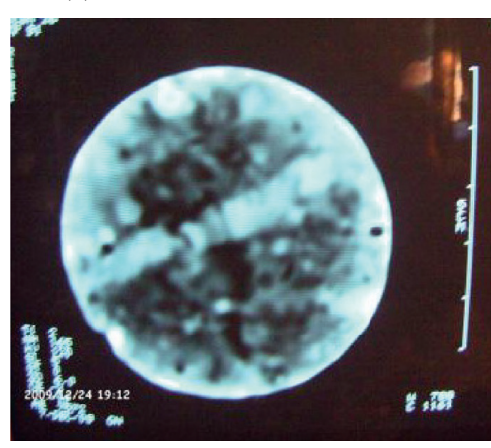

(d)

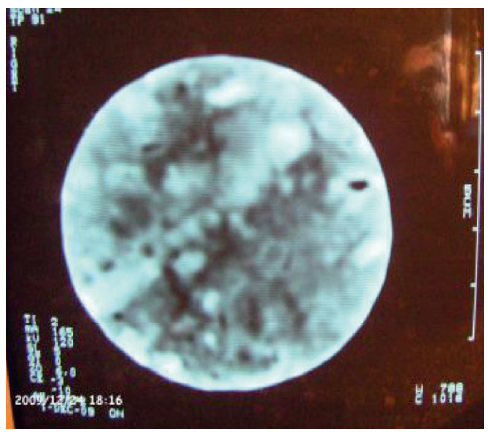

(b)

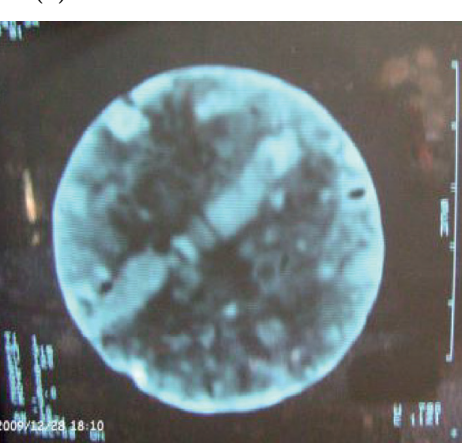

(e)

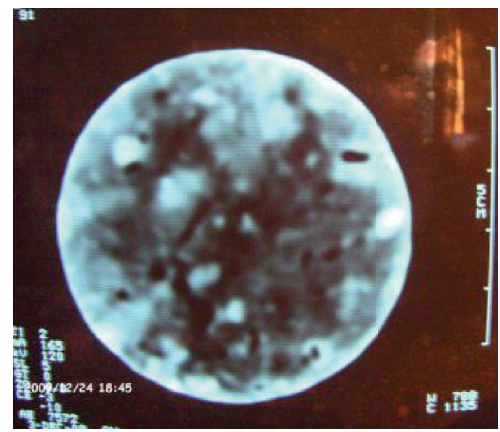

(c)

Figure 15: CT images of the $b$ section position of the LC-1 sample with cycle amplitude $\Delta w=10 \%$. (a) Zero cycles. (b) One cycle. (c) Two cycles. (d) Four cycles. (e) Six cycles. 


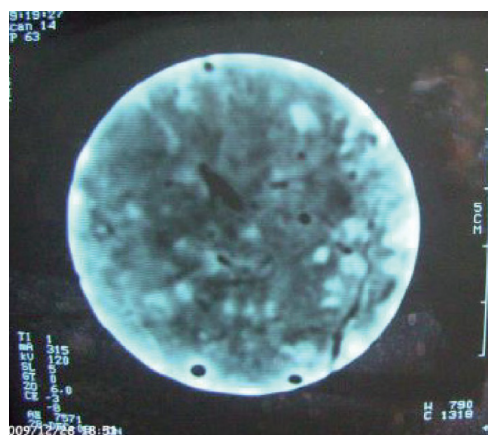

(a)

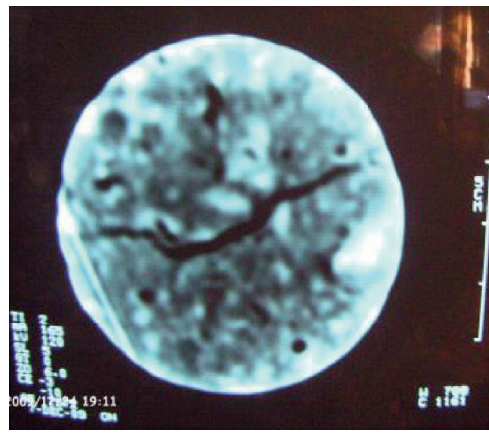

(d)

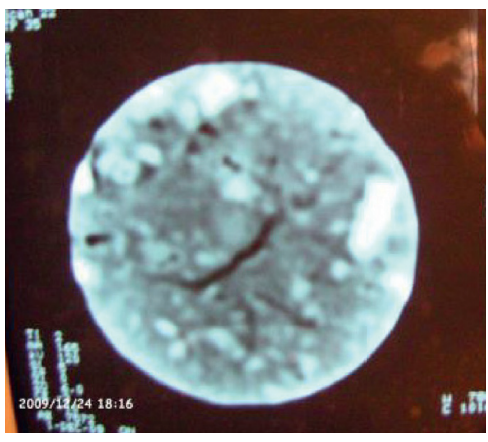

(b)

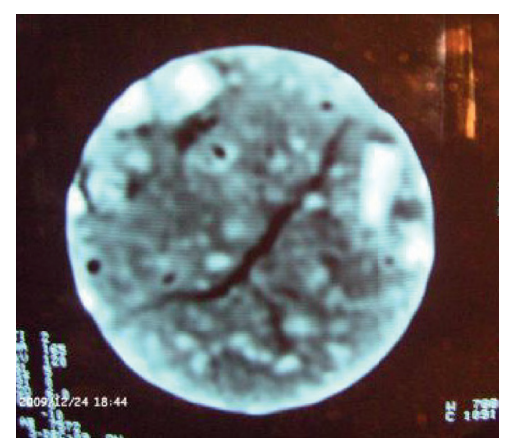

(c)

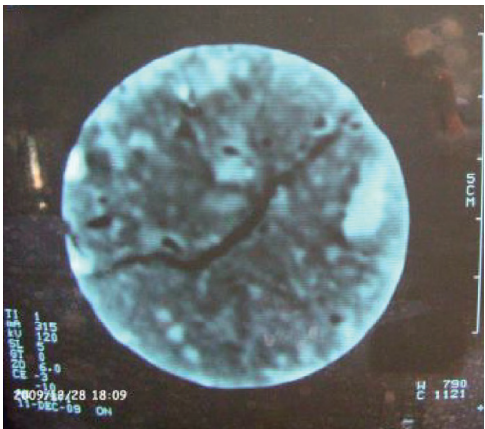

(e)

Figure 16: CT images of the $a$ section position of the LC-2 sample with cycle amplitude $\Delta w=20 \%$. (a) Zero cycles. (b) One cycle. (c) Two cycles. (d) Four cycles. (e) Six cycles.

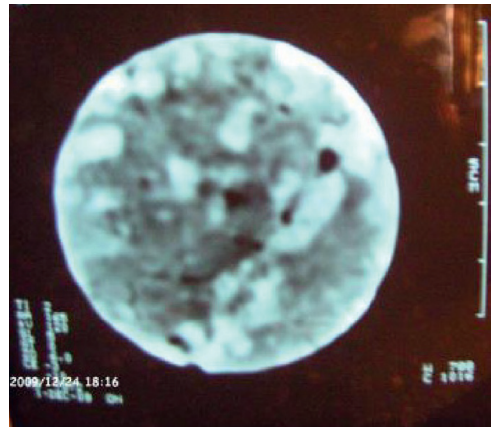

(a)

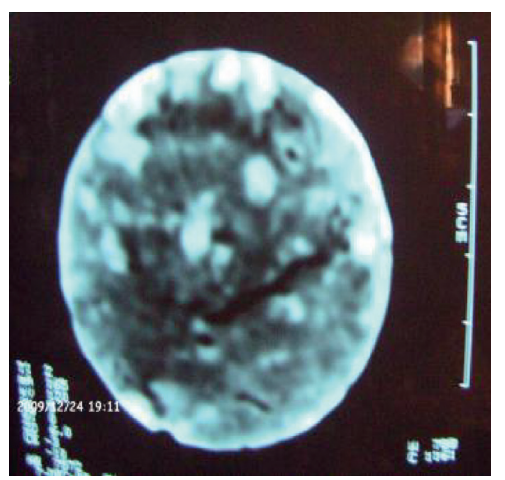

(d)

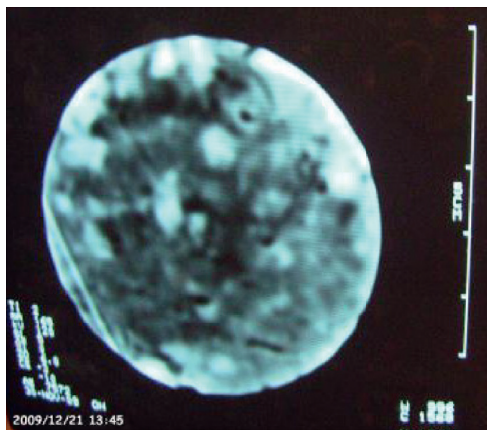

(b)

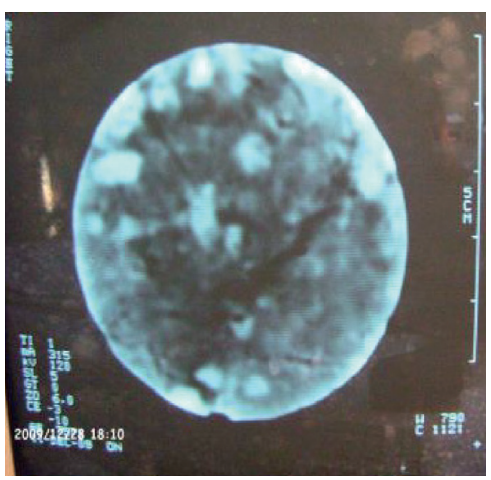

(e)

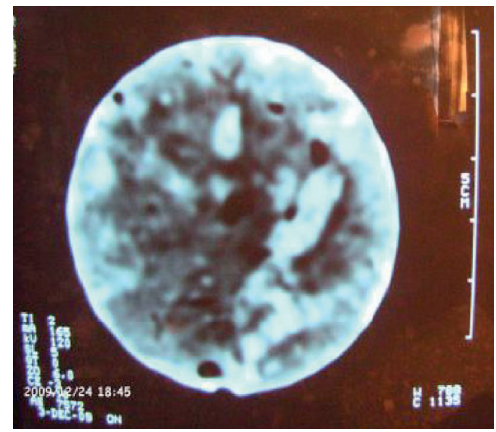

(c)

Figure 17: CT images of the $b$ section position of the LC-2 sample with cycle amplitude $\Delta w=20 \%$. (a) Zero cycles. (b) One cycle. (c) Two cycles. (d) Four cycles. (e) Six cycles. 
3.3. Quantitative Analysis of the CT Scan Results during DryWet Cycles. This section presents the LC-1 and LC-2 samples as examples. The samples were subjected to six drywet cycles with amplitudes of $\Delta w=20 \%$ and $\Delta w=10 \%$ and seven CT scans. To accurately obtain the change in CT number, the mean (ME) and standard deviation (SD) of the CT numbers measured in the test denote the ME of the upper and lower scan levels and the average SD of the CT values.

Figures 14-17 present the cross-sectional images of $a$ and $b$ during each scan. The photos were scanned during the initial state of the sample and after drying one, two, four, and six times.

The results in the figures show that the initial soil sample before drying exhibits nonuniform micropores and microcracks and other initial damage media. Under the action of a dry-wet cycle, the microporous cracks in the dried soil samples gradually develop and open. With an increase in the number of dry-wet cycles, the microcracks gradually elongate and widen, exhibiting irregular bifurcation and, finally, penetration and soil failure. This process reflects the entire process of the damage evolution of the soil's internal structure.

To accurately explain the development and evolution of the damage fractures in soil during a dry-wet cycle, the quantitative analysis of the CT numbers and the obtained changes in such numbers are used to clearly illustrate the full range of joint damage and fracture expansion evolution of loess. The change law of the mean values of CT number ME and SD is illustrated in Figure 18.

After the first dry-wet cycle, the ME and SD of the soil sample exhibited the highest decrement and increment, respectively, indicating that this cycle exerts the most evident effect on porosity, cracking, and degree of development inside loess. After the soil sample is humidified, the size of the micropores inside the soil sample gradually increases under the action of water. During the drying process, the water evaporates from the inside of the soil sample, and the microcracks expand (i.e., elongate and broaden). This phenomenon explains why the ME of the soil sample decreases and the SD increases. After two dry-wet cycles, the ME value increases, suggesting that the soil sample exhibits a dense realization during the dry-wet cycle. However, the increase in the SD value implies that the damage expansion characteristics continue and, thus, demonstrates the soil damage evolution. What mentioned above demonstrates the irregular characteristics of the soil damage evolution. After five dry-wet cycles, $\mathrm{ME}$ reaches the maximum value, but the SD value still increases linearly. This result indicates that before this, the soil sample was compact (i.e., the number of closed micropores in the soil sample was decreasing). Moreover, ME tends to decrease, whereas SD linearly increases, indicating that the meso damage of the soil sample is gradually evolving; that is, a new damage begins to develop based on the initial damage. The evolution reflects that cracks continue to open, and ME is decreasing. With an increase in the number of dry-wet cycles, when all the cracks are penetrated, the damage evolution of the internal cracks and fissures in the soil intensifies and eventually leads to the failure of the soil samples. The larger the amplitude, the larger the change in the ME and SD values, and the fewer the cycle times, leading to soil sample damage. In addition, the larger the amplitude, the faster the development of the fissures and cracks in the soil sample, exacerbating the damage evolution of the soil sample.

\section{Theoretical Analysis of Cracks in Soil under Water}

The causes of fissures in loess under the action of a dry-wet cycle were analyzed by combining the collapsibility of loess and the mechanical mechanism of fissure generation. Crack generation involves a change in the stress state of soil during the dewetting process. Negative stress appears on the surface of soil, inducing stress on soil. In accordance with theory, cracks are generated during the conversion of saturated soil to unsaturated soil. Therefore, three sets of stress tensor can be used for the analysis:

$$
\left.\begin{array}{l}
\left\{\sigma^{*}\right\}, s\{\delta\}, u_{a}\{\delta\} \\
\{\delta\}-u_{w}\{\delta\}, s\{\delta\}, u_{w}\{\delta\} \\
\left\{\sigma^{*}\right\},\{\sigma\}-u_{w}\{\delta\},\{\delta\}
\end{array}\right\}
$$

where $s$ is the matrix suction $\left(u_{a}-u_{w}\right)$, and $\left(u_{a}-u_{w}\right)$ is the net stress tensor.

The isotropic and linear elasticity assumptions can be expressed as

$$
\left.\begin{array}{l}
\varepsilon_{x}=\frac{\sigma_{x}-u_{a}}{E}-\frac{\mu}{E}\left(\sigma_{y}-\sigma_{z}-2 u_{a}\right)+\frac{u_{a}-u_{w}}{H} \\
\sigma_{x}=\sigma_{y}
\end{array}\right\},
$$

where $H$ is the elastic constant related to $\left(u_{a}-u_{w}\right)$.

Before cracking, the following condition must hold:

$$
\varepsilon_{x}=0 \text {. }
$$

Substituting this expression to derive the net horizontal stress yields

$$
\sigma_{x}-u_{a}=\frac{\mu}{1-\mu}\left(\sigma_{z}-u_{a}\right)-\frac{E}{H(1-\mu)}\left(u_{a}-u_{w}\right) .
$$

Surface soil $\sigma_{z}=0$; hence, the preceding formula can be given as

$$
\sigma_{x}-u_{a}=\frac{\mu}{1-\mu} u_{a}-\frac{E}{H(1-\mu)}\left(u_{a}-u_{w}\right)
$$

For any unsaturated soil, the strength $\sigma_{t}$ of the soil actually changes with the moisture content of the soil and is a function of the matrix suction. The relationship between the matrix suction and $\sigma_{t}$ is written as follows:

$$
\sigma_{h}-u_{a}=\frac{\mu}{1-\mu}\left(\sigma_{v}-u_{a}\right)-\frac{E}{(1-\mu) H}\left(u_{a}-u_{w}\right)=-\sigma_{t} \text {. }
$$




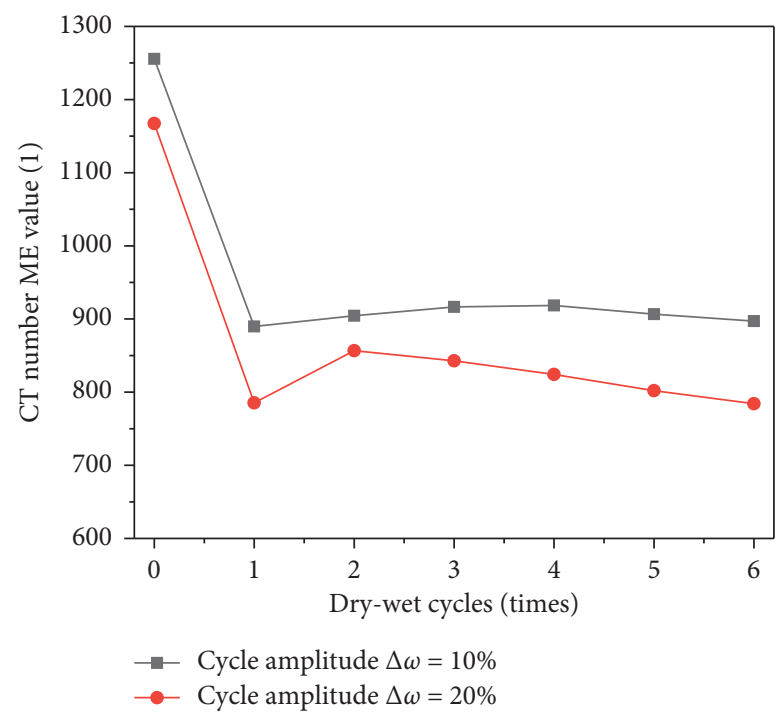

(a)

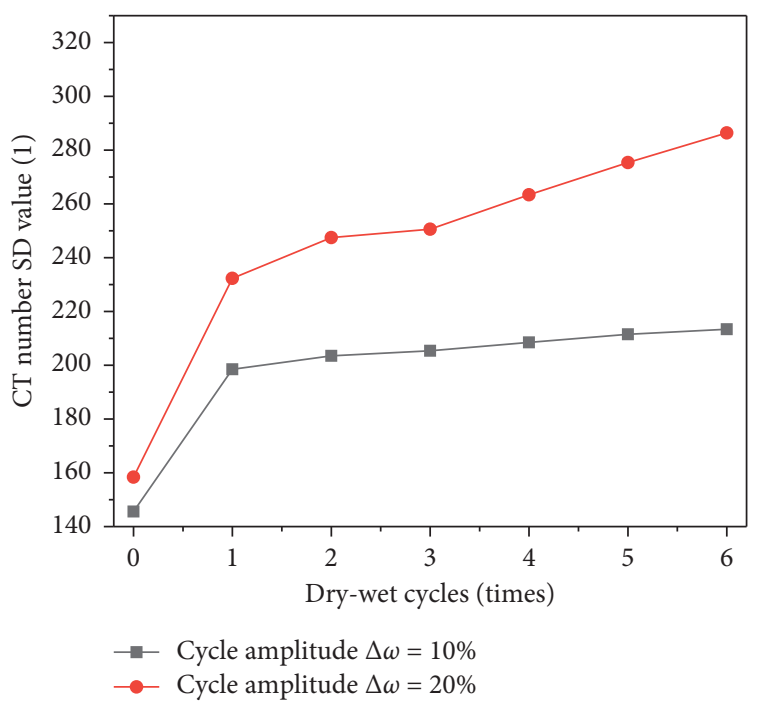

(b)

FIGURE 18: Relationship between the number of dry-wet cycles and CT number. (a) Change curve of CT number ME. (b) CT number SD curve.

In unsaturated soils, matrix suction exerts a certain effect on soil strength. The tensile strength of soil is calculated as

$$
\sigma_{t}=-0.5\left[c^{\prime}+\left(\mu_{a}-\mu_{w}\right) \tan \phi^{\prime}\right] \cot \phi^{\prime}
$$

where $\sigma_{t}$ is the tensile strength, $c^{\prime}$ is the cohesion of the soil, and $\phi^{\prime}$ is the internal friction angle of the soil.

The condition wherein the surface layer is under critical cracking is mathematically defined as

$$
\sigma_{x}-u_{a}=\sigma_{t}
$$

where $\sigma_{t}$ is the tensile strength of the topsoil.

From the preceding derivation, the stress state equation of soil cracking can be obtained as

$$
\begin{aligned}
& \left(\frac{\mu}{1-\mu}\right) u_{a} \\
& =\left[0.5 c^{\prime} \cot \phi^{\prime}+\left(0.5 \tan \phi^{\prime} \cot \phi^{\prime}-\frac{E}{(1-\mu) H}\right)\left(u_{a}-u_{w}\right)\right],
\end{aligned}
$$

where $\sigma_{v}=\sigma_{z}=0$ is the vertical total normal stress, $\sigma_{h}=\sigma_{x}$ is the horizontal total normal stress, $\mu$ is Poisson's ratio, $E$ is the elastic modulus related to the change in $\left(\sigma-\mu_{a}\right), H$ is the elastic modulus related to the change in $\left(u_{a}-u_{w}\right), u_{a}$ is the pore gas pressure, and $u_{w}$ is the pore water pressure.

The loess itself has collapsibility, disintegration, and permeability. These characteristics cause the soil to deform and destroy, and uneven deformation and fracture will produce cracks under certain conditions. According to the previous section and the theoretical analysis of the above-mentioned fissures, it is believed that the decrease of the water content in the soil increases the matrix suction $\left(u_{a}-u_{w}\right)$ in the soil, and when the magnitude of the matrix suction is greater than the tensile strength of the soil itself, fissures arise from the surface. It can be seen that the generation of cracks in the soil is closely related to the suction of the matrix inside the soil, and the change (saturation) of the water content in the soil is the main factor leading to the generation of cracks. Of course, the generation of cracks in the loess body is also related to the deterioration of the strength of the loess. The soil structure has various degrees of damage, and these cracks provide good channels for water infiltration or evaporation.

\section{Conclusion}

In this study, the structural degradation of loess is analyzed through the physical action of water, i.e., dry-wet cycles. The effects of this cycle on the structural and strength degradation of loess are investigated. The following conclusions are obtained from the micro and meso tests using hightechnology techniques.

(1) Using fractal theory and MATLAB to calculate fractal dimension, the evolution of the surface cracks of the soil sample is observed from a macro perspective. Studies have shown that the maximum fractal dimension $D$ occurs during the initial stage of a dry-wet cycle. With the increase of the number and amplitude of dry and wet cycles, the fractal dimension $D$ keeps increasing and the increasing amplitude gradually decreases. This result suggests that the surface crack development of the soil samples is at the maximum during the initial stage of a dry-wet cycle.

(2) The stress-strain curves of the undisturbed loess samples under different cycles are obtained by varying the stress-strain curves of the static triaxial tests on undisturbed loess under different numbers 
of dry-wet cycles and confining pressures. Evident differences are observed. Under the same axial strain, the stress value of undisturbed loess is higher than that of the loess sample after a dry-wet cycle, implying that the effect of the dry-wet cycle on loess strength is degraded.

(3) Using the obtained stress-strain curve, the relationship between the shear strength and index of loess and the number and amplitude of dry-wet cycles is determined. As the number and amplitude of dry-wet cycles increase, the shear strength of the loess sample, the cohesion value of the strength index, and the amplitude gradually decrease. With an increase in the number and amplitude of dry-wet cycles, the change in the internal friction angle of the strength index is inevident, indicating that the effect of dry-wet cycles on the internal friction angle of loess is insignificant.

(4) Through the CT scan test, the effect of dry-wet cycles on the development and evolution of existing cracks in the sample was analyzed from a meso-scale perspective. Studies have shown that, with an increase in the number and amplitude of dry-wet cycles, the ME value of CT decreases, whereas its SD value increases. The highest decrement of $\mathrm{ME}$ and the highest increment of SD are observed during the initial stage of a dry-wet cycle. In conclusion, dry-wet cycles promote the development of cracks.

(5) According to experiments and theoretical analysis, it can be known that the generation of cracks in soil is closely related to the suction of the matrix inside the soil, and the change in water content (saturation) in the soil is the main factor leading to the generation of cracks. Of course, the generation of cracks in the loess body is also related to the deterioration of the strength of the loess. The soil structure has various degrees of damage, and these cracks provide good channels for water infiltration or evaporation.

\section{Data Availability}

The data used to support the findings of this study are available from the corresponding author upon request.

\section{Conflicts of Interest}

The authors declare no conflicts of interest.

\section{Acknowledgments}

The authors gratefully acknowledge the financial support from the National Natural Science Foundation of China (Grant nos. 41672305 and 41902299) and the Key Science and Technology Program of Shaanxi Province (Grant no. 2017ZDXM-SF-082).

\section{References}

[1] B. Wen, Prediction and Disaster Mitigation Countermeasures of Typical Landslides in the Loess Area, Geological Publishing House, Beijing, China, 1997.

[2] J. Wang and Y. Li, Formation Mechanism and Disaster Mitigation of Thick Loess Landslides in Western China, Gansu Academy of Sciences Institute of Geological Natural Disasters, Lanzhou, China, 1996.

[3] N. F. Zhao, W. M. Ye, B. Chen, Y. G. Chen, and Y. J. Cui, "Modeling of the swelling-shrinkage behavior of expansive clays during wetting-drying cycles," Acta Geotechnica, vol. 14, no. 5 , pp. $1325-1335,2019$.

[4] K. Li, H. Nowamooz, C. Chazallon, and B. Migault, "Limit deformation analysis of unsaturated expansive soils during wetting and drying cycles," Soil Mechanics and Foundation Engineering, vol. 55, no. 1, pp. 33-39, 2018.

[5] G. J. Burton, J. A. Pineda, D. Sheng, and D. Airey, "Microstructural changes of an undisturbed, reconstituted and compacted high plasticity clay subjected to wetting and drying," Engineering Geology, vol. 193, pp. 363-373, 2015.

[6] E. Kalkan, "Impact of wetting-drying cycles on swelling behavior of clayey soils modified by silica fume," Applied Clay Science, vol. 52, no. 4, 2011.

[7] A. Y. Mady and E. V. Shein, "Assessment of pore space changes during drying and wetting cycles in hysteresis of soil water retention curve in Russia using X-ray computed tomography," Geoderma Regional, vol. 21, Article ID e00259, 2020.

[8] H. Yang and D. Xiao, "Effect of dry-wet cycle effect on shear strength of expansive soils," Journal of Changsha University of Science and Technology (Natural Science Edition), vol. 2, no. 2, pp. 1-5, 2005.

[9] F. Zhang and X. Chen, "Effect of repeated dry and wet cycles on mechanical properties of unsaturated soils," Chinese Journal of Geotechnical Engineering, vol. 1, no. 1, pp. 41-46, 2010.

[10] Y. Zhao, Z. Zeng, and L. ü Haibo, "The influence of dry and wet cycle on deformation index of expansive soil," Journal of Guilin Institute of Technology, vol. 29, no. 4, pp. 470-473, 2009.

[11] J. Zheng, C. Yan, and W. Xia, "Experimental study on the effect of dry-wet cycle on bearing strength of new solidified soil," Chinese Journal of Rock Mechanics and Engineering, vol. 28, no. 1, pp. 3051-3056, 2009.

[12] B. Gong, X. Zhou, and W. Zhou, "Study on the relationship between suction and strength during dry-wet cycle," Chinese Journal of Geotechnical Engineering, vol. 28, no. 2, pp. 207209, 2006

[13] X. Gan and H. Chen, "Study on the mechanical characteristics of the soil subgrade with mud and gravel under dry-wet cycle," pp. 67-68, Changsha University of Science and Technology, Changsha, China, 2005, Master's thesis.

[14] D. Zhang, Experimental Study on Humidification and DryWet Cycle of Soft Rock Coarse Grained Soil, Vol. 6, Tsinghua University, Beijing, China, 2007.

[15] L. Cao and X. Luo, "Experimental study on the strength characteristics of Qianjiangping landslide landslide soil in the Three Gorges Reservoir area under dry and wet cycling conditions," Rock and Soil Mechanics, vol. 28, no. Supplement, pp. 2791-2795, 2007.

[16] H. Yin, Q. Xu, and Z. Li, "Effect of shear strength on dryness and wet cycle variation on stability," Journal of Hydraulic Engineering, vol. 39, no. 5, pp. 568-579, 2008.

[17] H. Hu, F. Tao, and X. Li, "Application of fractal theory in geotechnical engineering," Mining Technology, vol. 6, no. 4, pp. 71-73, 2006. 